\title{
Analysis of Storm Pattern for Design Urban Drainage System in the Monsoon Areas of Vietnam
}

\author{
Bui Thi Thu Trang ${ }^{1}$, Nguyen Thi Hong Hanh ${ }^{1}$, Nguyen Thi Hoai Thuong ${ }^{1}$ and Nguyen Van Thuan ${ }^{2}$ \\ 1. Faculty of Environment, Hanoi University of Natural Resources and Environment, Hanoi 100000, Vietnam \\ 2. Department of General Affairs, State Audit Office of Vietnam, Hanoi 100000, Vietnam
}

\begin{abstract}
In Vietnam, rainfall data usually received using daily rainfall at all hydrology stations with higher time resolution are scarce. However, its analyses to achieve IDF (Intensity-Duration-Frequency) curves are often required at a finer scale such as hourly. Therefore, it needs to develop and apply methods to derive the IDF characteristics of short-duration events from daily rainfall statistics in Vietnam. In recent years, the need for new insights into the rainfall process leading to new approaches to model the distribution of rainfall intensities in time and space was recognized. This research aims to establish IDF curves for monsoon climate area in Vietnam based on scaling method. Scaling properties of extreme rainfall are examined in the Red River Delta of Vietnam in order to establish scaling behavior of statistical moments over different durations. Such scaling or scale-invariant models enable us to scale data from one temporal resolution to another, and thus, help to overcome the lack of the extreme rainfall data of sub-daily durations. The disaggregation or downscaling techniques are used to obtain sub-daily rainfall data from daily rainfall data for the derivation of scaled IDF curves. Research results show that most of rainfall amount (approximately $70 \%$ ) received from rains occurring between $6: 0 \mathrm{pm}$ to $6: 0 \mathrm{am}$ of the day after that, the daytime usually less rainfall occurrence with only $30 \%$. The peak rainfall is usually occurred during 0:0 am to $4: 0$ am having approximately $42.98 \%$ of rainfall amount over a day. The peak rainfall likely happen earlier in the recent year (36\% rainfall amount over a day occurrence from 6:00 pm to 10:00 pm in 2008). The analysis also illustrated that approximately $40 \%$ of rainfall events have duration less than 60 minutes. In contrast, only approximately $9 \%$ of rainfall events have duration more than 6 hours but total rainfall depths of these events is approximately.
\end{abstract}

Key word: IDF (Intensity-Duration-Frequency) curves, design rainfall for urban, design rainfall in the Monsoon areas.

\section{Introduction}

Vietnam has been significantly urbanized in recent years. The process of urbanization has been happening pretty soon from the medieval with the formation of feudal city, but for many reasons, that process took slowly and low level of residential development urban. However, in the last of twentieth century and beginning of twenty first century open up a new development of urbanization in Vietnam with growth of economic and rapidly increase of population associated which is formed on large scale, bulk, speed, industrial parks, export processing zones, new urban areas and significant improvement of infrastructure in both urban and rural areas.

Corresponding author: Bui Thi Thu Trang, Master, research field: water engineering and management.
Over the last 20 years, Vietnam has undergone a dramatic period of urbanization and the national urban system has been experiencing many changes. In 1990, there were only about 500 urban areas nationwide, but by 2000 this figure had increased to 649 and by 2003 it had reached 656 . The current urban system consists of 753 urban areas, including the two special urban areas of Ha Noi and Ho Chi Minh City. According to census data, during this period the proportion of people living in urban areas increased from $23.7 \%$ in 1999 to $29.6 \%$ in 2009 and one third of urban population are living in Ha Noi and Ho Chi Minh City, where are the cities expecting to triple by 2020 . The urbanization rate is $3.06 \%$ per annum and expected more (Urbanization in Vietnam: Evidence from the 2009 census, UNFPA report 2004).

The rapidly increasing of population and expand of 
urban areas while low investment of drainage infrastructure lead to more flooding occurs which has become in urban areas of Vietnam. Urban areas are requiring the protective structures, which can prevent or mitigate the occurrence of flood with the minimum costs. That is the most survival important of development and urbanization of Vietnam.

The IDF (Intensity-Duration-Frequency) relationship of heavy rainfall is one of the most important tools utilized by engineers for designing flood alleviation and drainage structures in urban and urban areas. The establishment of such relationship was done as early (eg., Sherman, 1931; Bernard, 1932). Since then, many sets of relationship have been constructed for several parts of the globe (e.g., Dickinson, 1977; Kothyari and Garde, 1992; Froehlich, 1995; Ferro and Bagarello, 1996). However, such relationships have not been constructed in Vietnam [1,2].

There is a high need for establishment of the IDF curves in Vietnam.

Local IDF equations are often estimated on the basis of records of intensities abstracted from rainfall depths of different durations, observed at a given recording rainfall gauging station.

In Vietnam, rainfall data usually received using daily rainfall at all hydrology stations and rainfall data at higher time resolution are scarce. However, rainfall data analyses to achieve IDF curves are often required at a finer scale such as hourly rather than daily. Therefore, it needs to develop and apply methods to derive the IDF characteristics of short-duration events from daily rainfall statistics in Vietnam.

In recent years, the need for new insights into the rainfall process leading to new approaches to model the distribution of rainfall intensities in time and space was recognized. Therefore, the study aims to establish IDF curves for monsoon climate area in Vietnam based on scaling method. Scaling properties of extreme rainfall are examined in the Red River Delta of Vietnam in order to establish scaling behavior of statistical moments over different durations. Such scaling or scale-invariant models enable us to scale data from one temporal resolution to another, and thus, help to overcome the lack of the extreme rainfall data of sub-daily durations. The disaggregation or downscaling techniques are used to obtain sub-daily rainfall data from daily rainfall data for the derivation of scaled IDF curves.

\section{Methodology}

\subsection{Rainfall Measurement}

Rainfall are measured by rain gauge and measured in term of depth, the values being expressed in inches or millimeters. Rain gauges are based on the simple idea of exposing in the open hollow cylindrical vessel with a bottom.

Rain gauge is the standard method collection. Based on the types of rain collection, the rain gauges are classified as: Standard rain gauge, Weighing precipitation gauge, Tipping bucket rain gauge, Optical rain gauge and Aucoustic rain gauge. Rain gauges are located to collect rain over a specified area, based on time of recording rainfall data will classified rain gauge to be: Daily rain gauge, Recording rain gauge and Tipping bucket rain gauge.

Most Hydrometeological Stations in Vietnam is using Optical rain gauges to recording rainfall data. The rainfall data is collected and saved in graphs as shown in Figs. 1, 2.

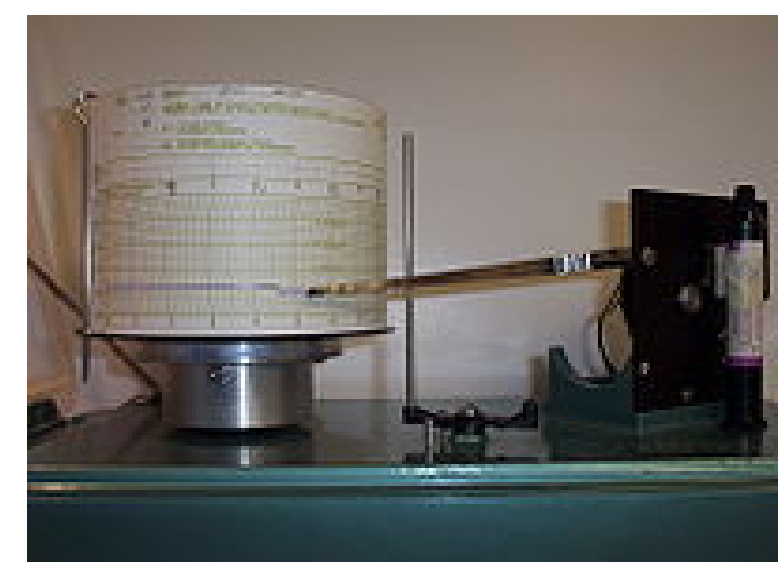

Fig. 1 Tipping bucket rain gauge recorder. 


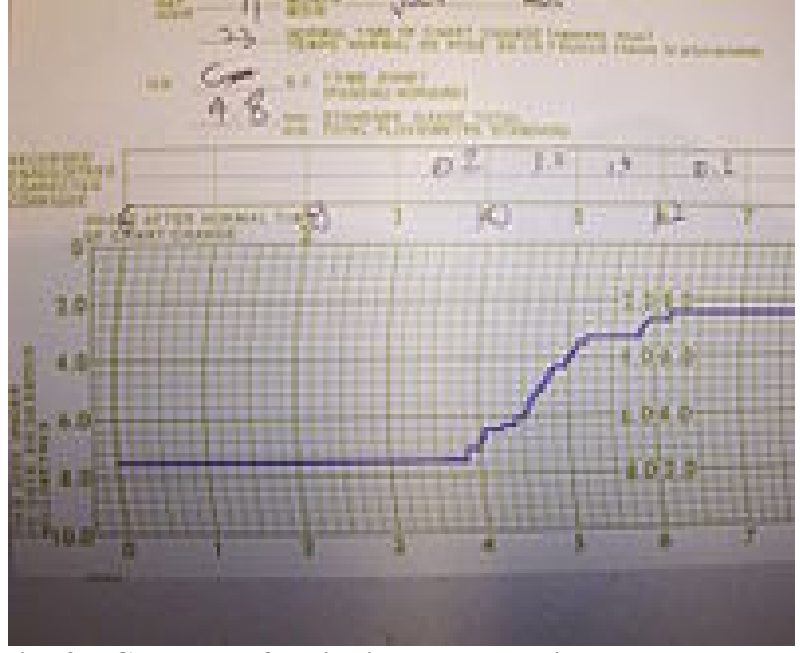

Fig. 2 Close up of a tipping bucket rain gauge recorder chart.

This research collected the rainfall data from two sources:

First one is the rainfall recorded at AIT meteorological station and WEM rain gauge, which can be recorded at minimum resolution of 1 minute. Rainfall data has recorded over period from 1990 to 2009.

Second one is rainfall data of Vietnam. The 30 year records (from 1956 to 1985) annual maximum daily rainfall were taken from Vietnam Institute of Meteorology and Hydrology (VNIMH). Five year hourly rainfall data of Lang Station (Ha Noi Capital) including 1984, 1995, 1996, 2002 and 2008 were available and collected.

\subsection{Rainfall Characteristics}

\subsubsection{Frequency Analysis}

The frequency analysis of rainfall data is meant to derive information from the historical. From the frequency analysis, estimates of magnitude of future events can be obtained.

\subsubsection{Return Period}

The recurrence interval or return period of a storm is the average time interval, usually in years, during which the given storm is likely to be equal or exceeded. The lengths of return periods from 2 years to 100 years are typically used for practical case. In this study, 2, 5, 10, 25, 50, 100 and 200 years return period are used.

\subsubsection{Distribution of Extreme Values}

There are many distributions which are commonly used to represent the distribution of maximum values. These distributions were can be used for fitting the maximum values: Gamma Distribution, Normal Distribution, Lognormal Distribution, Extreme Value Type I or Gumbel Distribution, Pearson Type III Distribution, Log Pearson Type III Distribution.

\subsubsection{Storm Duration}

The storm duration remains a problem for design engineers because of no accepted guidelines exist to define an appropriate duration. Watt, W. E. [3] concluded that for most small urban areas (up to 50 ha), the storm duration of 1 hour is quite suitable.

\subsubsection{Depth-Duration-Frequency Curve}

For any storm duration, one maximum value from every year will be selected to develop annual maximum series. Theoretically, The plotting of annual maximum rainfall and corresponding return period on extreme likelihood paper gives the Depth-Duration-Frequency curve which are the tails of the rainfall depth frequency distribution for various durations of storm.

\subsubsection{Intensity-Duration-Frequency Curve}

Rainfall Intensity-Duration-Frequency relationship gives the probability of obtaining rainfall intensity larger than specified intensity for a given duration. It can be determined from Depth-Duration-Frequency Curve by divided depth of rainfall by its considered duration.

Rainfall intensity duration frequency relationship comprises the estimates of rainfall intensities of different durations and recurrence intervals. The typical technique for establishment the IDF curves of precipitation is conducted via three steps.

\subsection{Single-site Temporal Disaggregation Model}

Because of daily precipitation data is most accessible and abundant source of rainfall information, 
it seems natural, at least for the regions where data at higher time resolution are scarce, to develop and apply methods to derive the IDF characteristics of short-duration events from daily rainfall statistics. In this regard and in contrast to earlier empirical disaggregation techniques, the works of Burlando, P. and Rosso, R. [4], Menable M. [5] and Nhat, L. M. [6] are examples of methodologies in which the theories of scaling properties and employed to infer the IDF characteristics of short-duration rainfall from daily data.

\subsubsection{Model Description}

Definition of disaggregation;

Generation of synthetic data (typically using stochastic methods);

Involvement of two scales (higher- and lower-level);

Use of different models for the two time scales (with emphasis on the different characteristics appearing at each scale);

Requirement that the lower-level synthetic series is consistent with the higher-level on;

Hyetos: A single variate fine time scale rainfall disaggregation model based on the modified Bartlett-Lewis process.

Modified Bartlett-Lewis (MBL) rectangular pulse model was considered due to its wide applicability for describing various different climates by

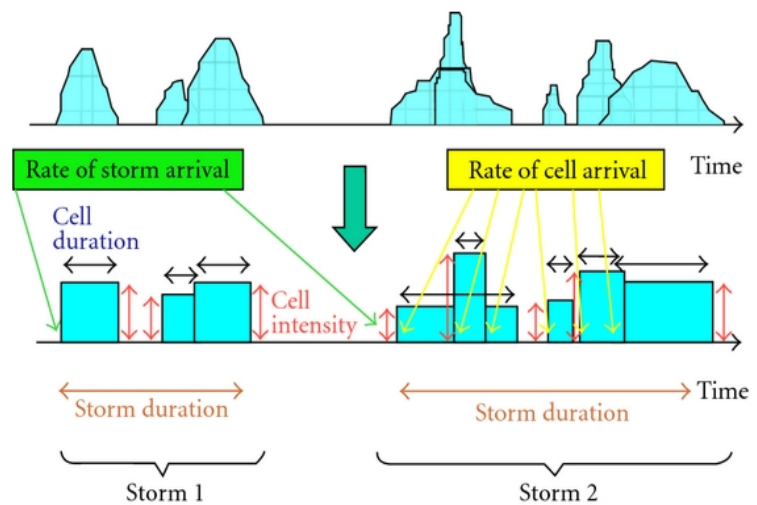

(a)
Rodriguez-Iturbe, I., et al. [7]. The diagram atic explanation of the MBL is depicted in Fig. 3.

\subsubsection{The Hyetos Model}

Hyetos is a package for the temporal stochastic simulation of rainfall process at fine time scales based on Bartlett-Lewis rectangular pulses rainfall mode.

This combines a rainfall simulation model based upon the Bartlett-Lewis process with proven techniques developed for the purpose of adjusting the finer scale (hourly) values so as to obtain the required coarser scale (daily) values. The methodology directly answers the question of the possible extension of the short hourly time-series with the use of longer-term daily data at the same point and provides the theoretical basis for an operational use of this methodology when no hourly data are available.

Repetition is first carried out to derive a synthetic rainfall series, which resembles the given series at the daily scale. This step focuses on the wet/dry pattern and the intensities separately. In a second step, an appropriate adjusting procedure - the proportional adjusting procedure - is applied to make the generated hourly series fully consistent with the given daily series without affecting the stochastic structure implied by the model.

The essential elements of the dynamic disaggregation model, described in detail by Koutsoyianis, D., et al. [8].

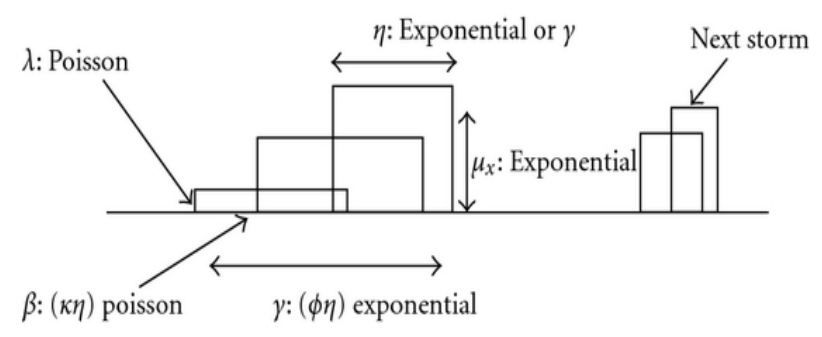

(b)

Fig. 3 (a) Explanatory sketch for the structures of rainfall storms; (b) Explanatory sketch for the parameters of Bartlett-Lewis rectangular pulses model. 
The disaggregation of a high-level variable, $\mathrm{Y}$ into its $\mathrm{k}$ components (low-level variables, $\mathrm{Yi}, \mathrm{i}=1 \ldots \mathrm{k}$ ), is performed in k-1 sequential steps.

At the beginning of the ith step, the amount-still-to-go, $\mathrm{Si}$, is known, and $\mathrm{Xi}$ is generated. The remaining quantity $\mathrm{Si}+1=\mathrm{Si}-\mathrm{Yi}$ is transferred to the next step.

In each step, the distribution function ( $\mathrm{Yi}, \mathrm{Si})$, conditional on previously generated information, is determined or approximated via conditional moments. It is assumed that the sequence of $\mathrm{Yi}$ has certain properties allowing the calculation of conditional moments, e.g. it is am autoregressive sequence.

The generation of $\mathrm{Yi}$ is performed by the so called bisection procedure, which can take several forms depending on the particular marginal distribution of the low-level variables.

\subsection{Scale Invariance Properties of Rainfall in Time Series}

The scaling or scale-invariant which enable to transform data from one temporal or spatial model to another one, thus help to solve the difficulty of inadequate data. A natural process fulfills the scaling property if the underlying probability distribution of some physical measurements at one scale is identical to the distribution at another scale, multiplied by a factor that is a power function of the ratio of two scales. The basic theoretical development of scaling has been developed by Gupta and Waymire [9].

\subsection{Derivation of IDF for Short Duration}

All forms of the generalized IDF relationships assume that rainfall depth or intensity is inversely related to the duration of a storm raised to a power, or scale factor 6 . There are several commonly used functions found in the literature of hydrology applications. Koutsoyiannis, D., et al. [8] have modified the IDF relationship for a given return period as particular cases, using Eq. (1):

$$
i=\frac{w}{(d+\theta)^{\eta}}
$$

Where I denotes the rainfall intensity for duration $\mathrm{d}$ and $w, \theta$ and $\eta$ represent non-negative coefficients. In fact, these arguments justify the formulation of Eq. (2) for the IDF relationships:

$$
i=\frac{a(T)}{b(d)}
$$

\subsection{Empirical IDF Formulas}

The IDF formulas are the empirical equations representing a relationship among maximum rainfall intensity (as dependant variable) and other parameters of interest such as rainfall duration and frequency (as independent variables). There are several commonly used functions found in the literature of hydrology applications [10] based on four form of equations used to describe the rainfall intensity duration relationship are summarized as Eqs. (3-6):

Talbot equation:

$$
i=\frac{a}{t_{d}+b}
$$

Bernard equation:

$$
i=\frac{a}{t_{d}^{c}}
$$

Kimijima equation:

$$
i=\frac{a}{t_{d}^{c}+b}
$$

Sherman equation:

$$
i=\frac{a}{\left(t_{d}+b\right)^{c}}
$$

Where $i$ is the rainfall intensity ( $\mathrm{mm} /$ hour); $t_{d}$ is the storm duration (minutes); $a, b$ and $c$ are the constant parameters related to the metrological conditions. 
These empirical equations show rainfall intensity decreases with rainfall duration for a given return period. All functions have been widely use for hydrology practical applications. The least-square method is apply to determine the parameters of the four empirical IDF equations that are use to represent intensity duration relationships. The value of parameters in the rainfall IDF equations are chose on minimum of RMSE (Root Mean Square Error) between the IDF relationships produce by the frequency analysis and simulate by the IDF equation.

\subsection{Design Storm Pattern}

Design storm is a rainfall event, which is developed for the design of specific type of objects, such as drainage systems or retention basins. There are several rainfall pattern used in many countries.

The main objective of this study is that to propose an optimal and suitable temporal rainfall pattern for urban drainage design in Vietnam. The main difficulty related to the determination of a suitable storm pattern for design purposes has been confirmed by the availability of various synthetic design storm models developed and used around the world. The Chicago model was the first developed in U.S. by Keifer, C. J. and Chu, H. H. [11] in 1957, and it was followed by other alternatives such as the pattern proposed by Sifalda, V. [12], Yen, B. C. and Chow, V. T. [13] and the balanced model suggested by the U.S. Army Corps of Engineers (1982). In Vietnam, rainfall design is not identical and there are also several methods such as: experimental model by Ministry of Construction, models based on formulas by Russia, Europe Union etc..

There are two main types of synthetic design storm, one is design storm derived from IDF relationships and the other one is design storm resulted from analyzing and synthesizing the characteristics of historical storm data. Based on these types of design storm, different synthetic design storm models available in various countries all over the world:
US Chicago storm model pattern by Keifer, C. J. and Chu, H. H. [11];

US Normalized storm pattern by Huff, F. A. [14];

Czechoslovakian storm pattern by Sifalda, V. [12];

US storm pattern by Yen, B. C. and Chow, V. T. [13];

Canadian temporal rainfall patterns by Nguyen, $\mathrm{V}$. T. V. [15];

Canadian storm model by Watt, W. E., et al. [3].

In this study, Chicago design storm, Silfada, V. [15] design storm will be apply at the monsoon areas of Thailand and Vietnam. This method described by Keifer, C. J. and Chu, H. H. [11] uses IDF curves for design hyetograph at given location. In general, the purposed storm pattern is fitted to exponential growth and decay curves with the intense part of the storm defined by a parameter, storm advance coefficient. This method was developed in Chicago for urban sewer design but can easily be used in other areas where adequate rainfall records are available.

\section{Data Analysis}

\subsection{Data Collection}

This study collected the rainfall data from two sources. First one is the rainfall recorded at AIT meteorological station and WEM rain gauge, which can be recorded at minimum resolution of 1 minute, and length of record during the period from 1990 to 2009.

Second one is rainfall data of Vietnam. The 30 year records (from 1956 to 1985) annual maximum daily rainfall and were taken from VNIMH (Vietnam Institute of Meteorology and Hydrology).

Five year include 1984, 1995, 1996, 2002 and 2008 when heavy rainfall occurred, hourly rainfall data is available but only in Lang Station, which is located in Ha Noi capital. The length of record for recording rain gauges is list in Table 1, and the position of rain gauges presented in Fig. 4 as shown.

Rainfall data in Vietnam was recorded in 7 stations where are located in the whole Red River Delta in 
Vietnam. The Red River and Thai Binh River systems are two main river systems in the North of Vietnam have a basin area of $169,000 \mathrm{~km}^{2}$ (Fig. 4). The Red River Delta area is $5,540 \mathrm{~km}^{2}$, annual rainfall strongly varies over the Red river area in a range 1,200-2,500 $\mathrm{mm} /$ year.

Seven rainfall stations includes Lang, Bac Giang, Hai Duong, Thai Binh, Nam Dinh, Ninh Binh and Van Ly which are located in the Red River Delta (Fig. 5) was collected.
3.2 Analysis of Rainfall Characteristics in Lang Station

\subsubsection{The Percentage of Rainfall Depth}

The percentage of rainfall depth in a day for each year is calculated based on the average percentage of rainfall depth of 4 years 1984, 1995, 1996, 2002 and 2008 which are the year with very high value of extreme rainfall and hourly rainfall data available at Lang Station (1984 and 2008, total rainfall depth are 2,189 $\mathrm{mm}$ and 2,276 $\mathrm{mm}$ respectively).

Table 1 List of recording rain gauges.

\begin{tabular}{|c|c|c|c|c|c|}
\hline Station & Latitude & Longitude & Elevation & Duration & No of year record \\
\hline Lang & $21^{\circ} 01^{\prime}$ & $105^{\circ} 48.0^{\prime}$ & 5.2 & \multirow{7}{*}{ 24-hour } & \multirow{7}{*}{$\begin{array}{l}30 \text { years } \\
(1956-2085)\end{array}$} \\
\hline Hai Duong & $20^{\circ} 5.6^{\prime}$ & $106^{\circ} 18.8^{\prime}$ & 3.2 & & \\
\hline Bac Giang & $21^{\circ} 17^{\prime}$ & $106^{\circ} 12^{\prime}$ & 7.1 & & \\
\hline Thai Binh & $20^{\circ} 2.7^{\prime}$ & $106^{\circ} 21.8^{\prime}$ & 2.3 & & \\
\hline Nam Dinh & $20^{\circ} 2.6^{\prime}$ & $106^{\circ} 10.8^{\prime}$ & 2.1 & & \\
\hline Ninh Binh & $20^{\circ} 1.4^{\prime}$ & $105^{\circ} 58.8^{\prime}$ & 3.6 & & \\
\hline Van Ly & $20^{\circ} 02^{\prime}$ & $106^{\circ} 30.0^{\prime}$ & 2.3 & & \\
\hline
\end{tabular}

Source: Vietnam Institute of Meteorology and Hydrology.

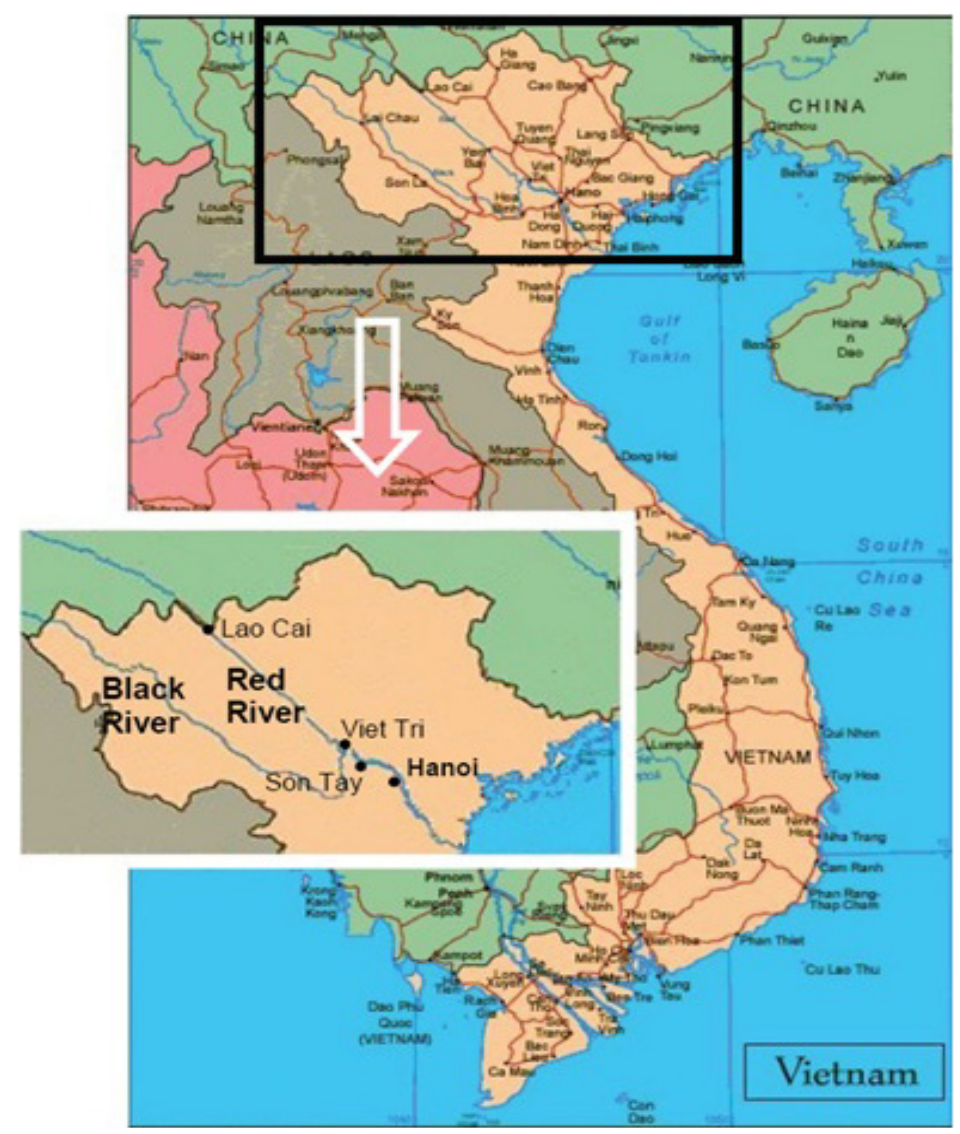

Fig. 4 Location of Red River Delta—Vietnam. 


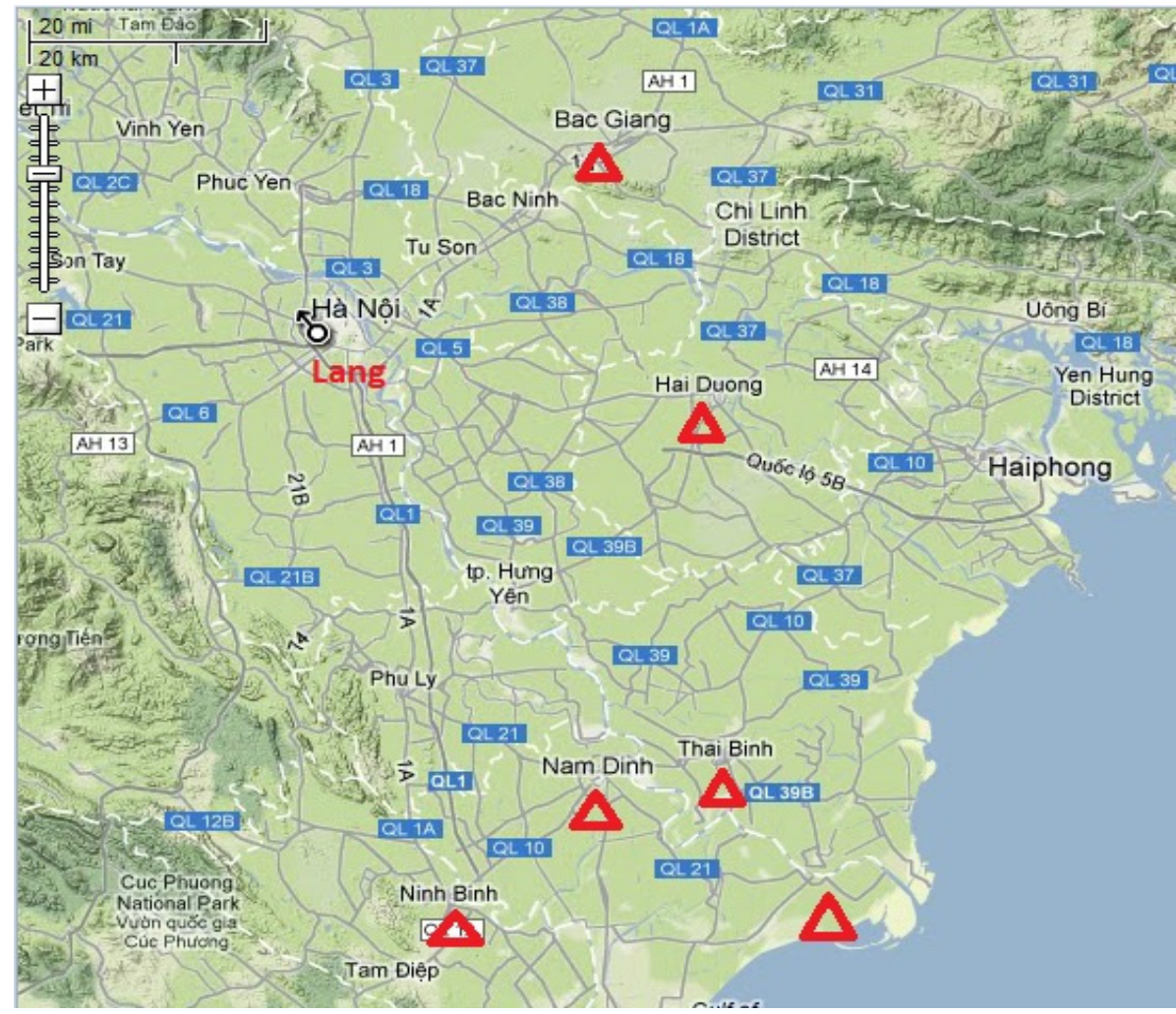

Fig. 5 Record rain gauges network map (rectangular shape is rain gauges stations).

Average percentage of rainfall depth over a day shows that the rainfall usually occurs from 18:00-6:00 with more than $70.0 \%$, and during 9 hour of day time from 07:00-17:00, rainfall not much occurs only $30.0 \%$. And one peak time of 1984 at 2:0 am with $13.3 \%$ of rainfall amount occurs and the other in 2008 at 20:0 with $9.05 \%$.

\subsubsection{Distribution of Rainfall Duration}

The annual number of storms occurred in Lang Station usually varies between 261 and 350 . The total annual rainfall depth range from 1,200 to $2,500 \mathrm{~mm}$, the average annual rainfall is $1,662.4 \mathrm{~mm}$ during the period form 1956 to 1985 . The maximum monthly rainfall depth recorded in Lang is $664.8 \mathrm{~mm}$ (Aug. 1972).

There are 5 year (1984, 1995, 1996, 2002 and 2008), which were the year with more flood occurred in Ha Noi, therefore hourly was available and used for many research in order to study about flooding.

In 1984, there were 326 storms was occurred and total rainfall depth was $2,189 \mathrm{~mm}$. There were 5 days with total daily rainfall depth more than $100 \mathrm{~mm}$ and special in 9th Nov. 1984, has an storms with total depth is $573.9 \mathrm{~mm}$. Both of this extreme value occurred in the same storm, 10th Nov. 1984 total depth of this event is $413 \mathrm{~mm}$ (18.9\% of total rainfall depth this year) with 31 hour of duration.

There is a significantly change in rainfall characteristics in Lang Station in comparison between 1984 and 2008. Consider the period from 1984 to 2008, Fig. 6 clearly show that the number of storm events which has storm duration more than 6 hours is decrease ( $10.4 \%$ to $8.8 \%$ ). In contrast, amount of these storm events increase from $59.7 \%$ to $64.8 \%$. It seems like that more extreme rainfall occurrence in the recent years, potently leading to more flood in Ha Noi Capital.

The research result show that the storm event occurred at 10th November 1984 which recorded in Lang Station with peak was $163.3 \mathrm{~mm}$, storm duration was 31 hour and rainfall depth was $413 \mathrm{~mm}$. The storm event occurred at 19th September 1984 which 
Table 2 Number of storm and total rainfall depth in Lang Station in 1984.

\begin{tabular}{lllll}
\hline $\begin{array}{l}\text { Duration } \\
\text { (hr) }\end{array}$ & $\begin{array}{l}\text { Number } \\
\text { of storm }\end{array}$ & $\begin{array}{l}\text { Total } \\
\text { depth } \\
(\mathrm{mm})\end{array}$ & $\begin{array}{l}\text { Percentage of } \\
\text { storm events } \\
(\%)\end{array}$ & $\begin{array}{l}\text { Percentage } \\
\text { of depth } \\
(\%)\end{array}$ \\
\hline$<1 \mathrm{hr}$ & 139 & 112.9 & 40.4 & 5.2 \\
$2 \mathrm{hr}$ & 83 & 186.8 & 24.1 & 8.5 \\
$3 \mathrm{hr}$ & 34 & 161.1 & 9.9 & 7.4 \\
$4 \mathrm{hr}$ & 19 & 268.4 & 5.5 & 12.3 \\
$5 \mathrm{hr}$ & 35 & 153.5 & 10.2 & 7.0 \\
$6 \mathrm{hr}$ & 13 & 65.6 & 3.8 & 3.0 \\
$>6 \mathrm{hr}$ & 21 & $1,240.4$ & 6.1 & 56.7 \\
Total & 344 & 2,189 & $100 \%$ & $100 \%$ \\
\hline
\end{tabular}

Table 3 Number of storm and total rainfall depth in Lang Station in 2008.

\begin{tabular}{lllll}
\hline $\begin{array}{l}\text { Duration } \\
\text { (hr) }\end{array}$ & $\begin{array}{l}\text { Number } \\
\text { of storm }\end{array}$ & $\begin{array}{l}\text { Total } \\
\text { depth } \\
(\mathrm{mm})\end{array}$ & $\begin{array}{l}\text { Percentage of } \\
\text { storm events } \\
(\%)\end{array}$ & $\begin{array}{l}\text { Percentage } \\
\text { of depth } \\
(\%)\end{array}$ \\
\hline$<1 \mathrm{hr}$ & 122 & 112.9 & 41 & 5 \\
$2 \mathrm{hr}$ & 66 & 209.5 & 22 & 9 \\
$3 \mathrm{hr}$ & 35 & 212 & 12 & 9 \\
$4 \mathrm{hr}$ & 21 & 75 & 7 & 3 \\
$5 \mathrm{hr}$ & 27 & 632.6 & 9 & 28 \\
$6 \mathrm{hr}$ & 9 & 192.1 & 3 & 8 \\
$>6 \mathrm{hr}$ & 18 & 841.7 & 6 & 37 \\
Total & 298 & 2,276 & $100 \%$ & $100 \%$ \\
\hline
\end{tabular}

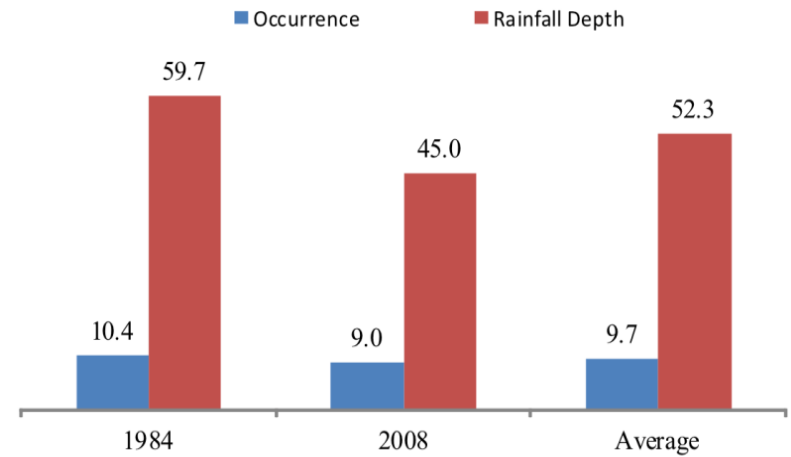

Fig. 6 Percentages of storm duration more than 6 hours in 1984/2008.

recorded in Lang Station with peak was $66.5 \mathrm{~mm}$, storm duration was 10 hour and rainfall depth was $217.2 \mathrm{~mm}$. The storm event occurred at 17th July 2008 which recorded in Lang Station with peak was $47.3 \mathrm{~mm}$, storm duration were 5 hours and rainfall depth was $130.9 .2 \mathrm{~mm}$. In 2008, total rainfall depth was $2,276 \mathrm{~mm}$ and there were 2 days with total rainfall depth more than $100 \mathrm{~mm}$ per day. The maximum daily and hourly rainfall depths were 391.2 and $69.9 \mathrm{~mm}$ respectively. Also, both of this extreme value occurred in the same storm, 31 st Oct. 2008. The storm event occurred at 17th July 2008 which recorded in Lang Station with peak was $47.3 \mathrm{~mm}$, storm duration were 5 hours and rainfall depth was 130.9.2 $\mathrm{mm}$.

3.2.3 Analysis Trend of Annual Total Rainfall Depth at Lang Station from 1956 to 1985

The relationship between annual rainfall depths from 1956 to 1985 and years which is expressed in Equation below:

$$
\text { Annual total rainfall depth: }
$$$$
Y=0.602 X^{2}-5.0433 X+1506.3
$$

The trend shows that annual rainfall significantly increased during the period from 1956 to 1985 as shown in Fig. 7.

According to available rainfall depth data during the period from 1956 to 1985 in Hanoi presented in this chart, we can see that the trend annual rainfall is increasing and ranging from 1,200 to 2,500 (mm/year) as shown in Fig. 8.

\subsection{Disaggregation of Daily Rainfall into Hourly Depths}

Hyetos is a package for the temporal stochastic simulation of rainfall process at fine time scales based on Bartlett-Lewis rectangular pulses rainfall mode. A simple and generic model that performs disaggregation of daily into hourly rainfall is presented. It combines an existing rainfall simulation model of the Poisson cluster type along with an appropriate technique for modifying the rainfall model output, thus performing disaggregation. Specifically, it uses the Bartlett-Lewis rectangular pulses rainfall model as a background stochastic model for rainfall generation.

The daily rainfall data used were taken from VNIMH (Vietnam Institute of Meteorology and Hydrology). The annual rainfall is varying from $1,200-2,500 \mathrm{~mm} / \mathrm{year}$, with a yearly total of between 121 and 185 days with rain. For the simulation of the 


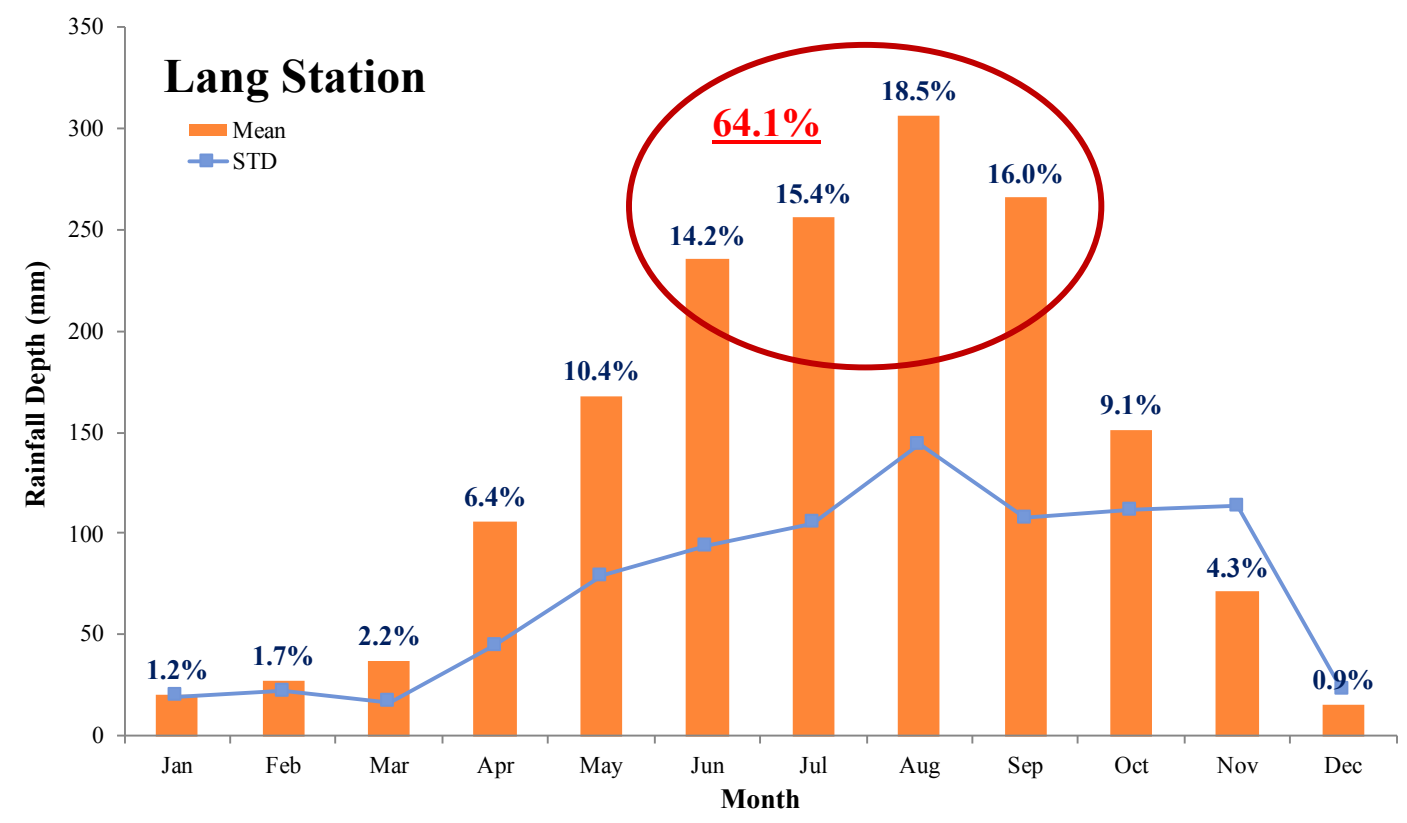

Fig. 7 Average monthly rainfall depth in Lang Station during the period 1956-1985.

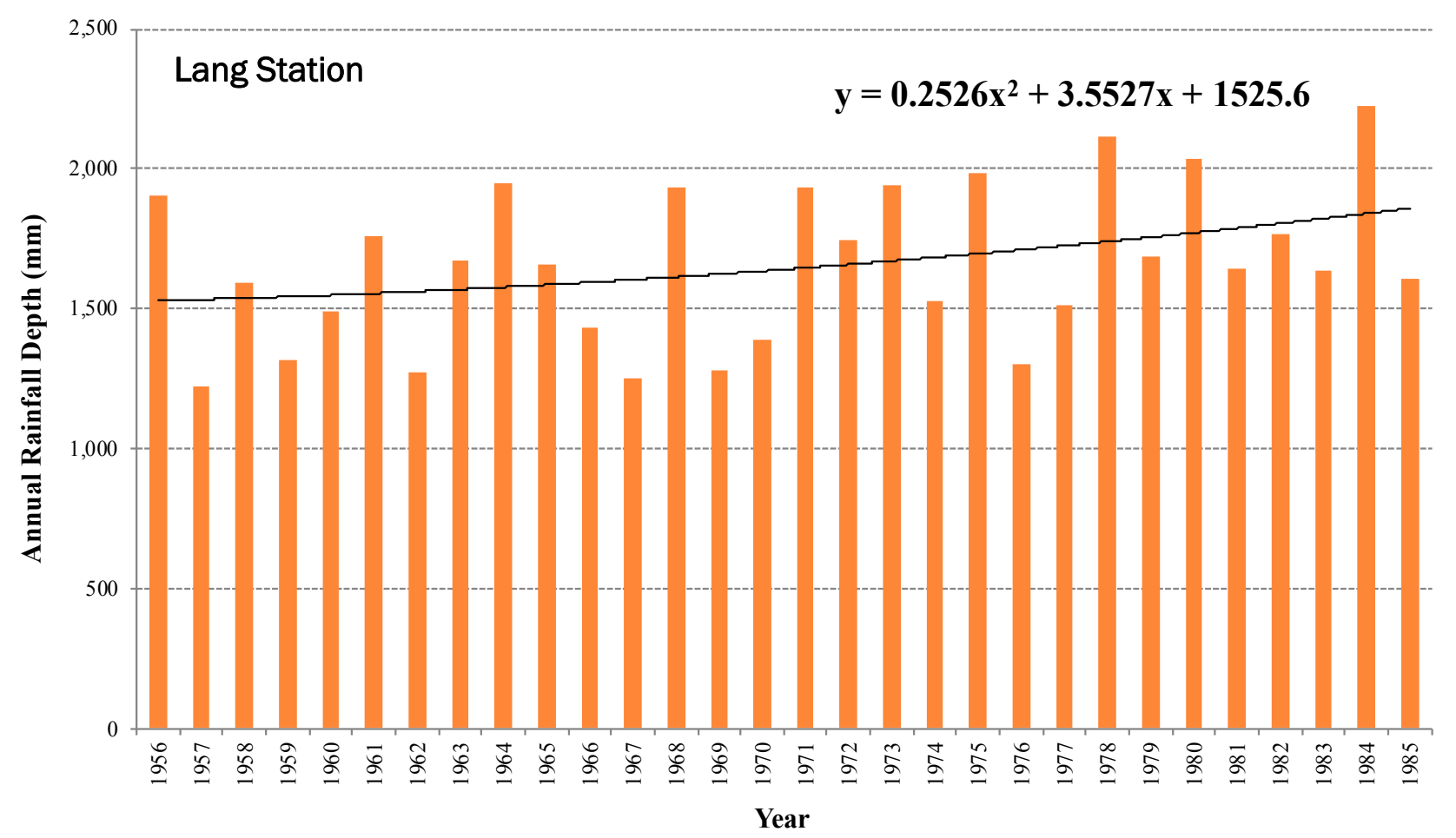

Fig. 8 Annual rainfall depth in Lang Station from 1956 to 1985.

series of hourly rainfall the stochastic model adopted was the modified Bartlett-Lewis rectangular pulse model with 6 parameters. The resolution of the hourly data was of the order of $0.1 \mathrm{~mm}$, and whenever the precipitation observed during an interval of time was less than this, the interval was defined as dry. To consider the seasonal variance of the values of precipitation, the parameters of the model are estimated separately for each month. The set of five parameter for the model has estimated and is shown in Table 4. 
Table 4 Parameter estimation for hyotes model estimation.

\begin{tabular}{llllll}
\hline Station & $\kappa$ & $\Lambda$ & $\Psi$ & $\eta$ & $\theta$ \\
$($ Kappa $)$ & (lambda) & $(\mathrm{psi})$ & $\begin{array}{l}\eta \text { (eta) } \\
\text { (theta) }\end{array}$ \\
\hline Lang & 0.15 & 15.74 & 4.00 & 0.779 & 0.289 \\
Nam Dinh & 0.15 & 16.29 & 3.31 & 0.749 & 0.259 \\
Thai Binh & 0.15 & 16.48 & 3.38 & 0.696 & 0.184 \\
Hai Duong & 0.15 & 15.37 & 4.20 & 0.768 & 0.279 \\
Bac Giang & 0.15 & 14.67 & 3.98 & 0.810 & 0.259 \\
Ninh Binh & 0.15 & 16.57 & 3.38 & 0.751 & 0.260 \\
Van Ly & 0.15 & 16.79 & 3.39 & 0.189 & 0.189 \\
\hline
\end{tabular}

From daily rainfall depth, five parameters of the model including above were estimated as in Table 4, by applying Hyetos model, research had disaggregate annual maximum daily rainfall depth to sub-daily rainfall data. Fig. 9 is annual maximum rainfall depth for various durations from one hour to 24 hours.

\subsection{Establishment of IDF Curves}

In order to examine the time scale invariance of rainfall, the analysis was performed on annual maximum rainfall series for storm durations from 1 hour to 24 hours, with $\lambda d=1,2 \ldots 24$. For each year the $\mathrm{E}[\mathrm{id}]$ measure is calculated for fixed values $\mathrm{q}=0,1,2$, 3,4 and 5. Then, for each $\mathrm{q}$ the ensemble average is calculated over the length of data record. The scaling properties of average singular measures are tested. By fitting with a line of $E\left[I_{d}^{q}\right]$ versus durations in $\log -\log$ plot we obtain the value of the $K(q)$ function for fixed q. It is shown in Fig. 10.

Fig. 11 shows the relationships between the log-transformed values of moment of various orders against values durations. For all four stations, the straight-line behavior with the R2 is equal 0.1 . The slope of the regression line between $K(q)$ and $q$ is $\eta=$ 0.7495 , as an estimated for the scale factor.

Table 5 shows that The IDF relationship for short duration rainfall can be deduced from daily data with $\eta=0.7495$ for Lang Station and with the estimates of $\mu \mathrm{D}$ and $\sigma \mathrm{D}$ with $\mathrm{D}=24$-hours. From 24-hour data collected at the Lang recording gauge Station, the sample of 21 year of 24-hour annual maximum rainfall intensity yields. The estimates $\mu \mathrm{D}=24=5.75$ and $\sigma \mathrm{D}=24=2.00$, and then $\mu=\lambda^{\eta} \mu_{24}=48.71$ and $\sigma=\lambda^{\eta} \sigma_{24}=21.68$.

Annual maximum rainfall depth for 2, 5, 10, 25, 100 and 200 years return period for the particular duration at Lang Station was calculated based on IDF relationships and expressed in Table 6.

Based on this equation, the parameter for 8 stations were estimated and shown in the Table 5. By applying the parameter into the general equation to estimate the

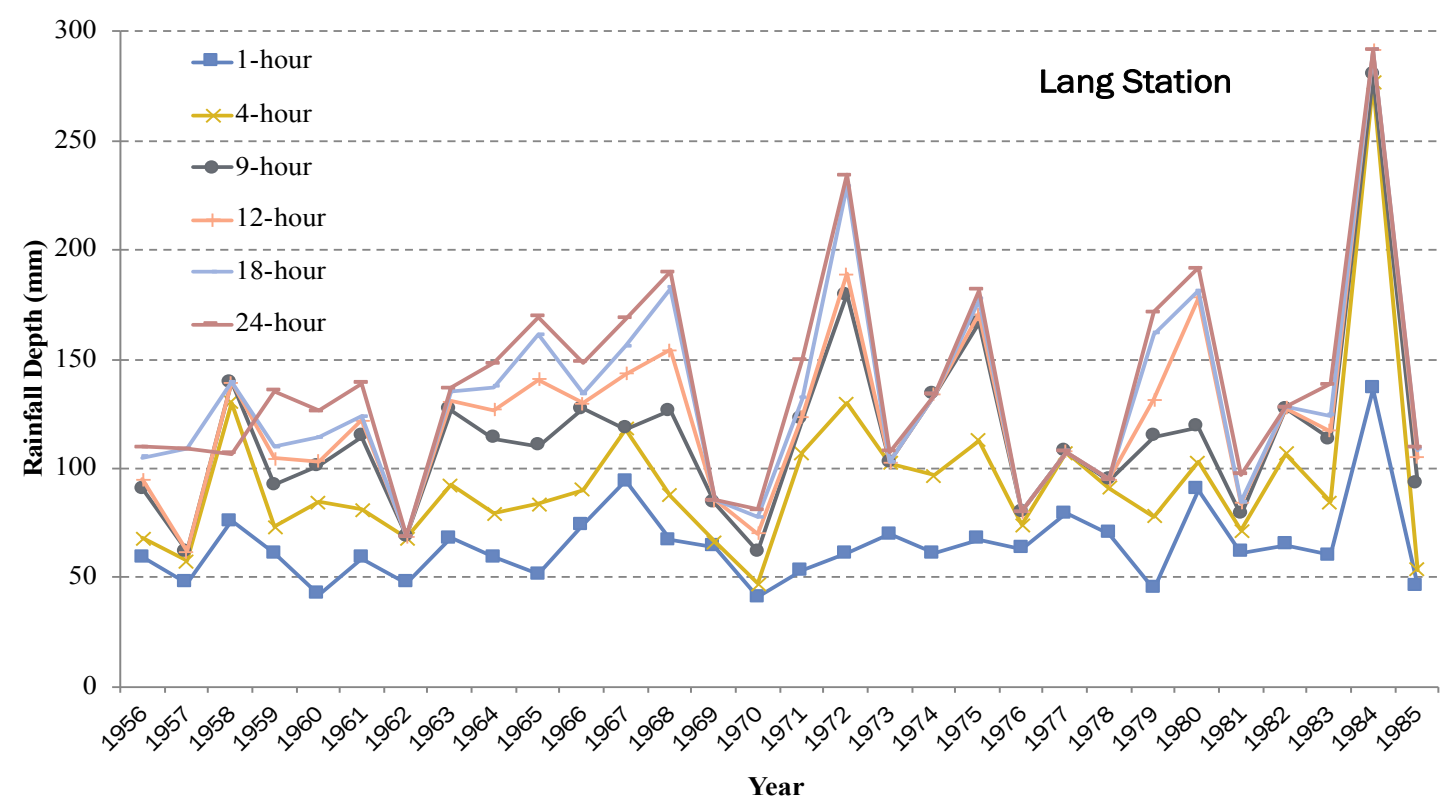

Fig. 9 Annual maximum rainfall depth for various durations. 


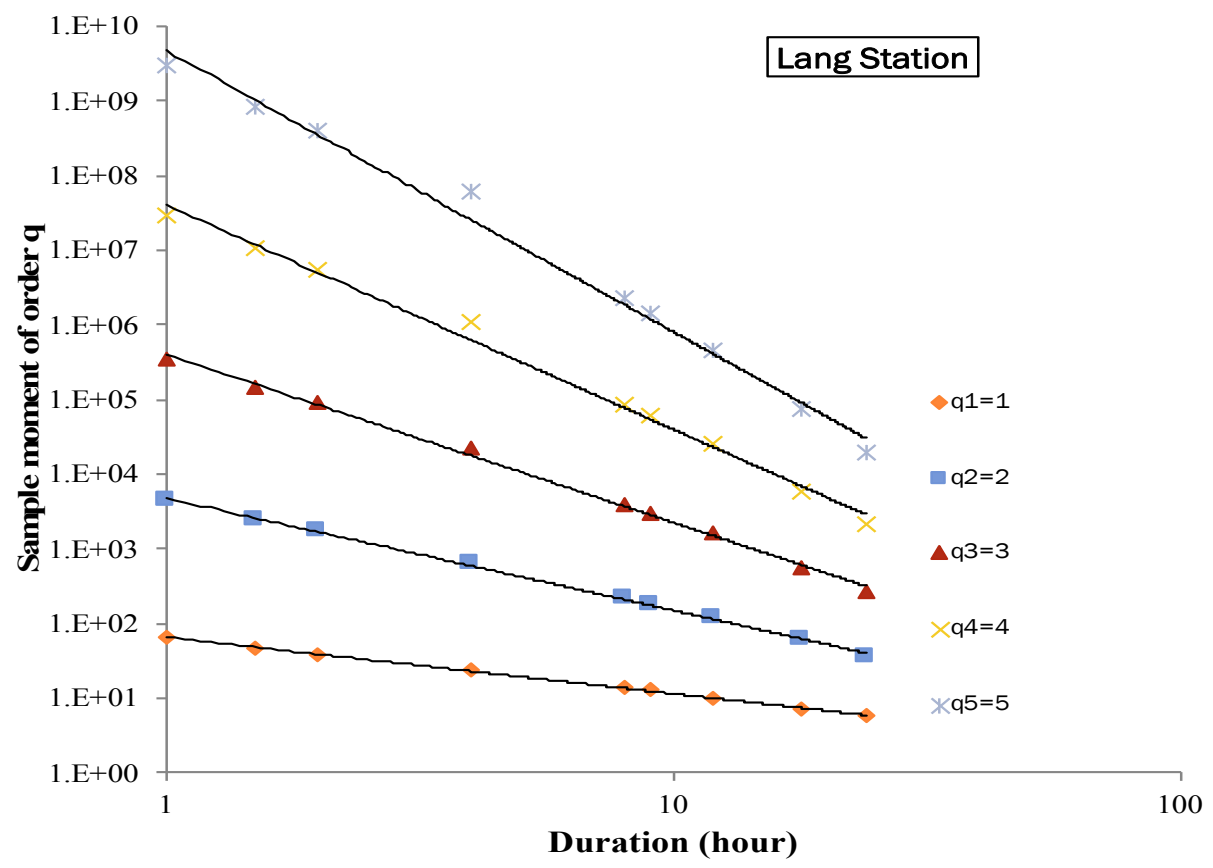

Fig. 10 Relationship between sample moments of order $q$ and duration.

\section{Sample moment of order $q$}

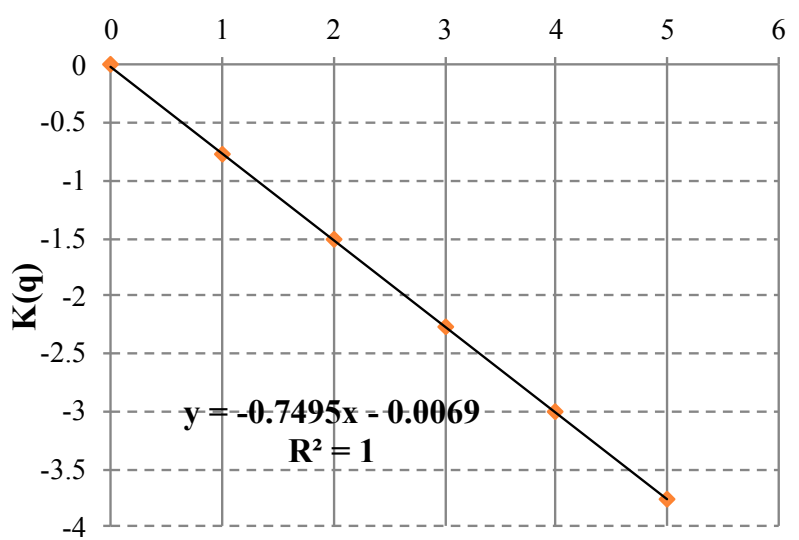

Fig. 11 Sample moments of order q.

Table 5 Parameter of IDF formulas at seven station.

\begin{tabular}{llll}
\hline Station & $\mu$ & $\sigma$ & $\eta$ \\
\hline Lang & 48.71 & 21.68 & 0.7495 \\
Nam Dinh & 65.09 & 24.94 & 0.7769 \\
Thai Binh & 50.36 & 22.44 & 0.6252 \\
Bac Giang & 41.99 & 20.42 & 0.7125 \\
Ninh Binh & 41.28 & 22.67 & 0.5884 \\
Van Ly & 50.56 & 25.29 & 0.6515 \\
Hai Duong & 51.41 & 18.32 & 0.6872 \\
WEM-AIT & 41.62 & 3.95 & 0.803 \\
\hline
\end{tabular}

maximum intensity rainfall for various duration and return period for 8 stations. After that, researchers have achieved the IDF curves which be shown in Fig.12-19.
In order to examine the possibility of applying scale method in other monsoon climate area, Thailand for example, researchers have applied the method with twenty year-maximum-daily rainfall recorded in AIT station. IDF curves are shown in Fig. 19.

\subsection{Graphical Evaluation}

Another traditional way of constructed rainfall IDF curves by Kimijima Equation. Frequency analysis techniques are used to develop the relationship between the rainfall intensity, storm duration, and return periods from rainfall data. 
Table 6 Maximum rainfall depth ( $\mathrm{mm}$ ) for various durations and return period based on IDF relationship at Lang Station.

\begin{tabular}{lllllllll}
\hline $\begin{array}{l}\text { Duration } \\
\text { Return periods }\end{array}$ & 1 & 2 & 4 & 8 & 9 & 12 & 18 & 24 \\
\hline 2 & 56.66 & 67.41 & 80.19 & 95.39 & 98.25 & 105.59 & 116.88 & 252.62 \\
5 & 81.24 & 96.64 & 114.96 & 136.76 & 140.86 & 151.38 & 167.57 & 180.09 \\
10 & 97.50 & 115.99 & 137.99 & 164.15 & 169.07 & 181.70 & 201.13 & 216.16 \\
25 & 118.06 & 140.45 & 167.08 & 198.76 & 204.71 & 220.01 & 243.53 & 261.73 \\
50 & 133.31 & 158.59 & 188.66 & 224.43 & 231.16 & 248.43 & 274.99 & 295.53 \\
100 & 148.45 & 176.60 & 210.08 & 249.92 & 257.40 & 276.64 & 306.21 & 329.09 \\
200 & 163.53 & 194.54 & 231.43 & 275.31 & 283.55 & 304.74 & 337.32 & 362.53 \\
\hline
\end{tabular}

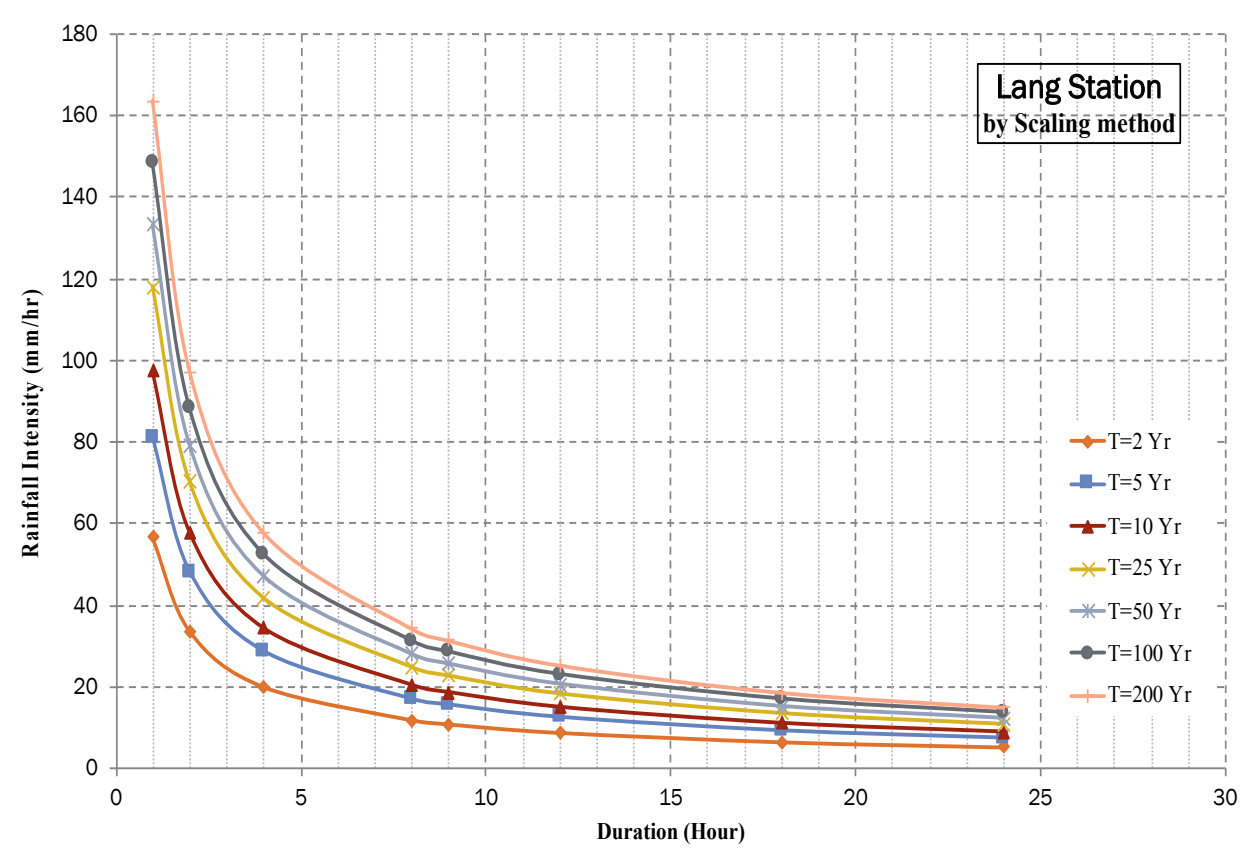

Fig. 12 The Rainfall IDF (Intensity-Duration-Frequency) curves for LANG station by Scaling method.

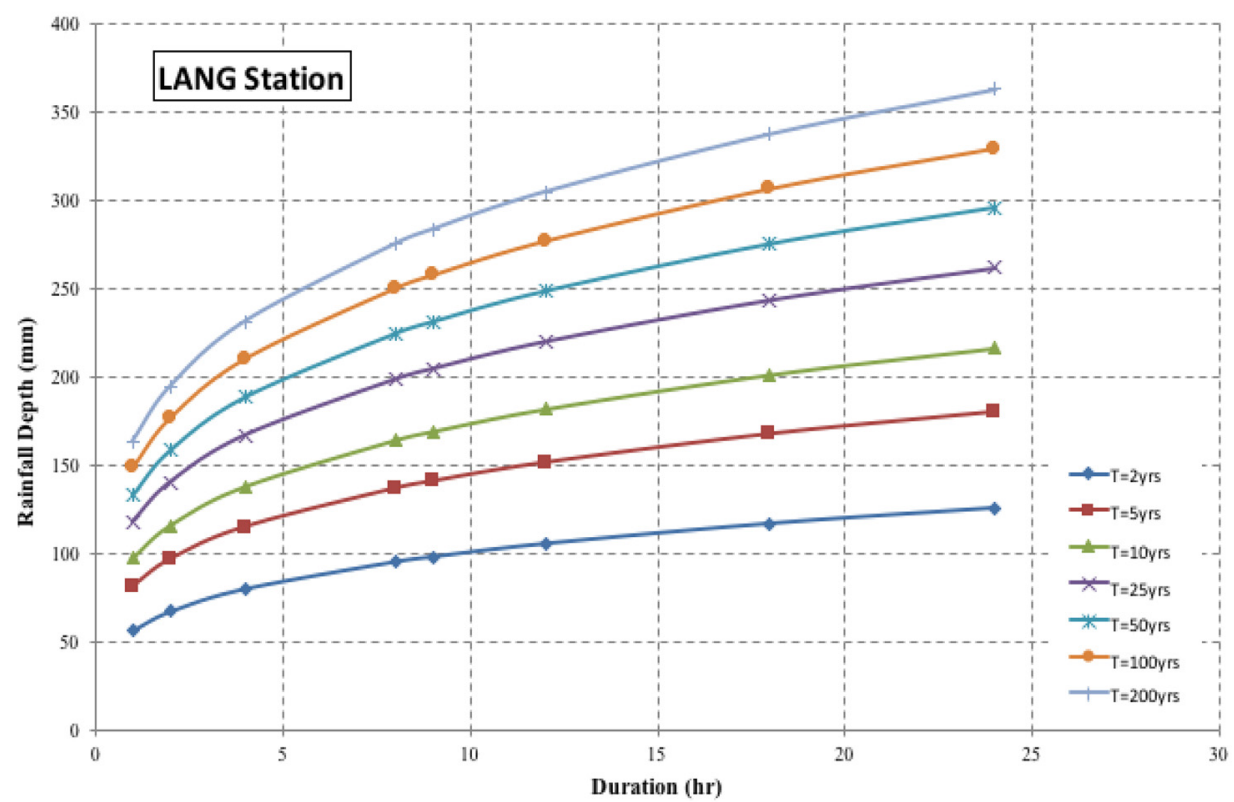

Fig. 13 The Rainfall DDF (Depth-Duration-Frequency) curves for LANG station by Scaling method. 


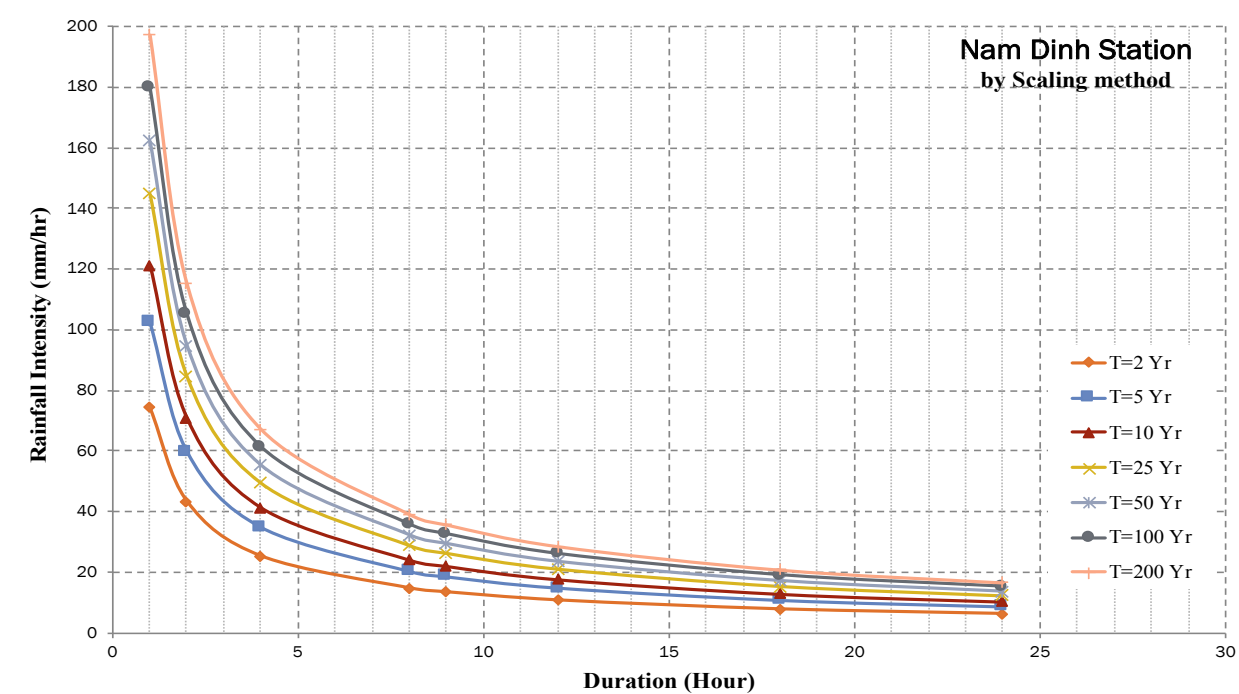

Fig. 14 IDF curves in Nam Dinh Station for various return period.

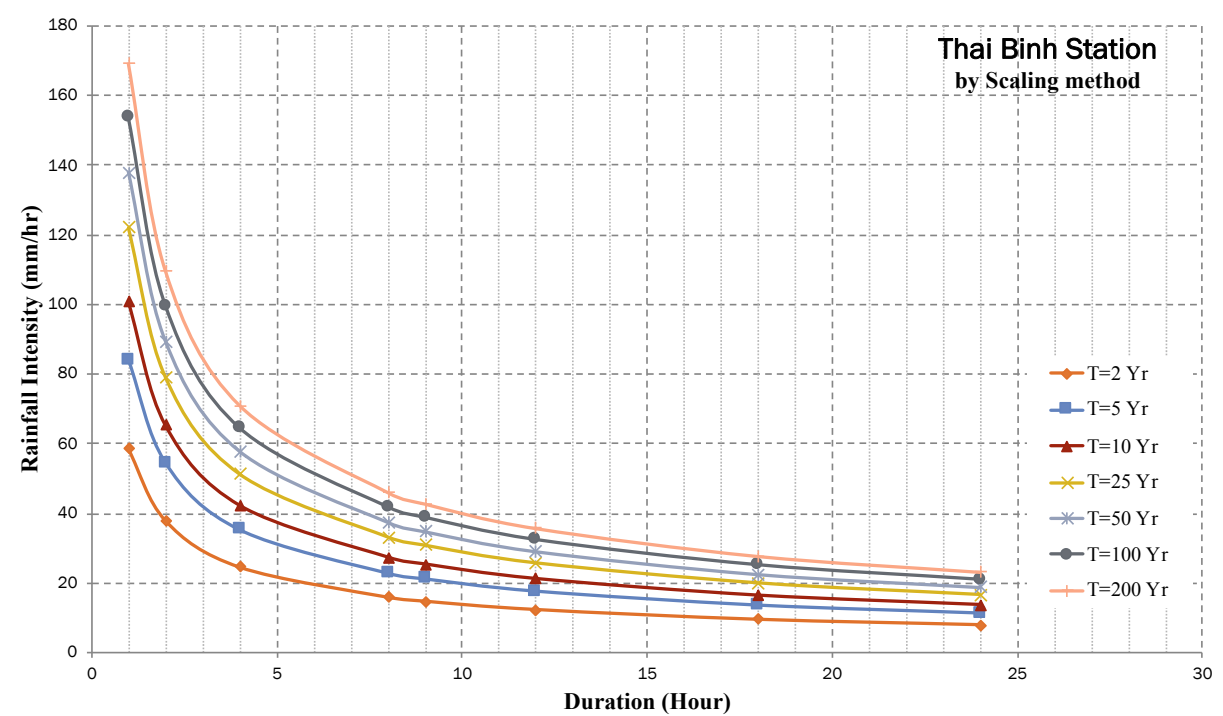

Fig. 15 IDF curves in Thai Binh Station for various return period.

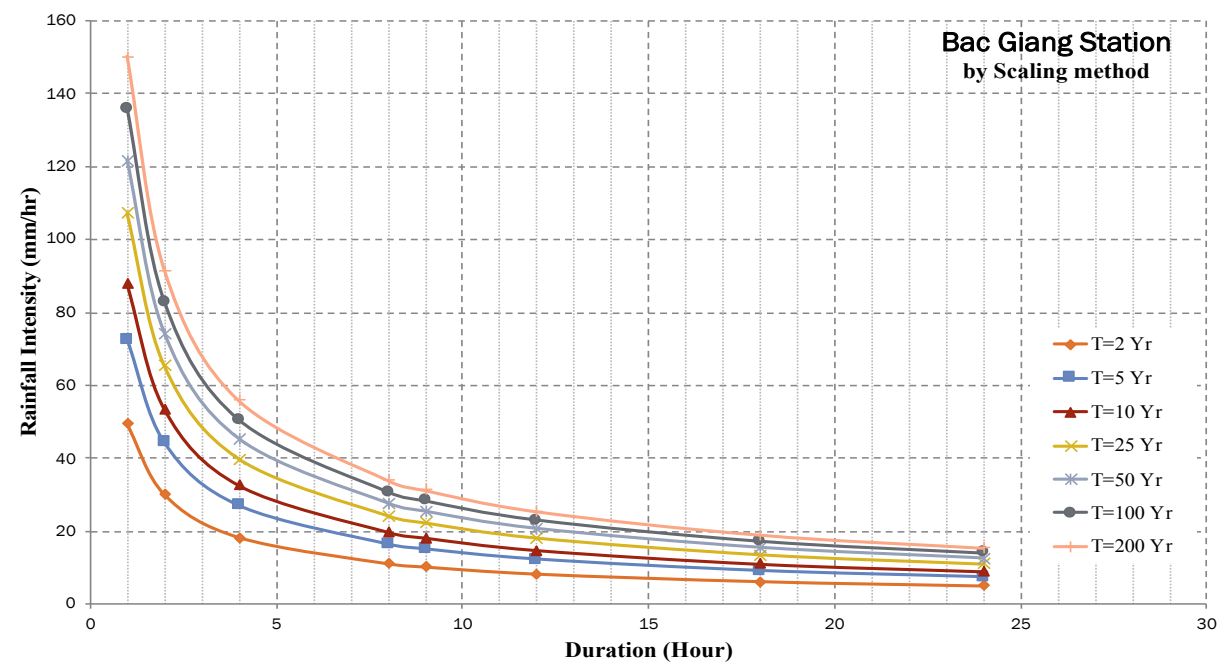

Fig. 16 IDF curves in Bac Giang Station for various return period. 


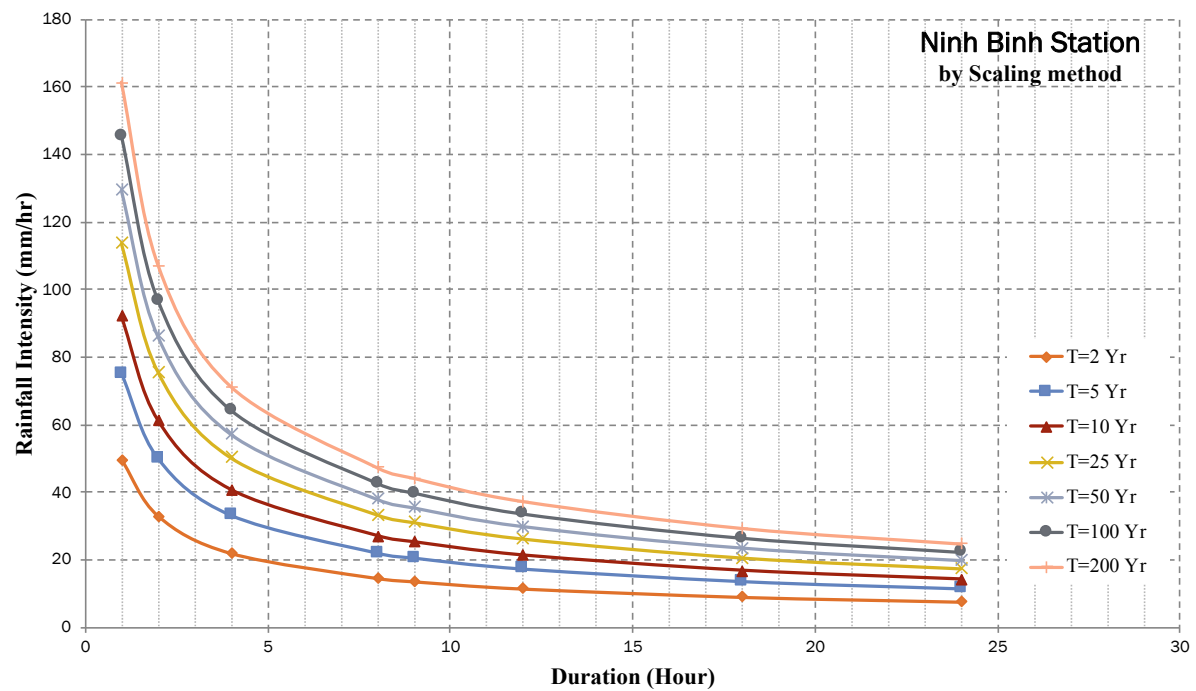

Fig. 17 IDF curves in Ninh Binh Station for various return period.

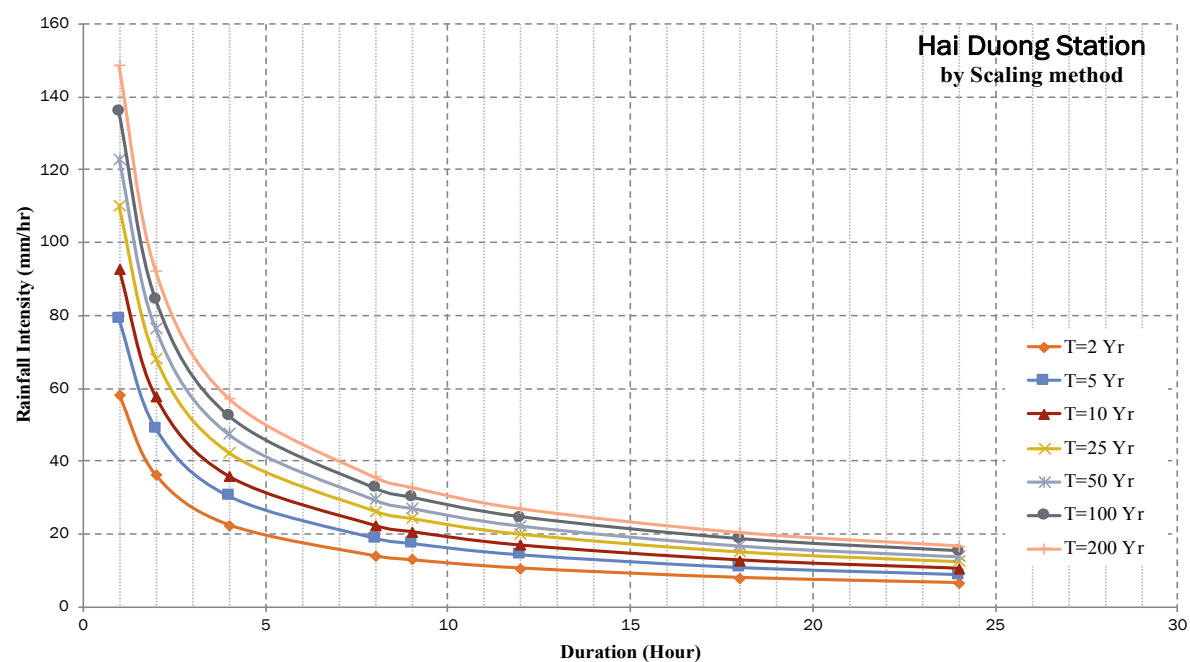

Fig. 18 IDF curves in Hai Duong Station for various return period.

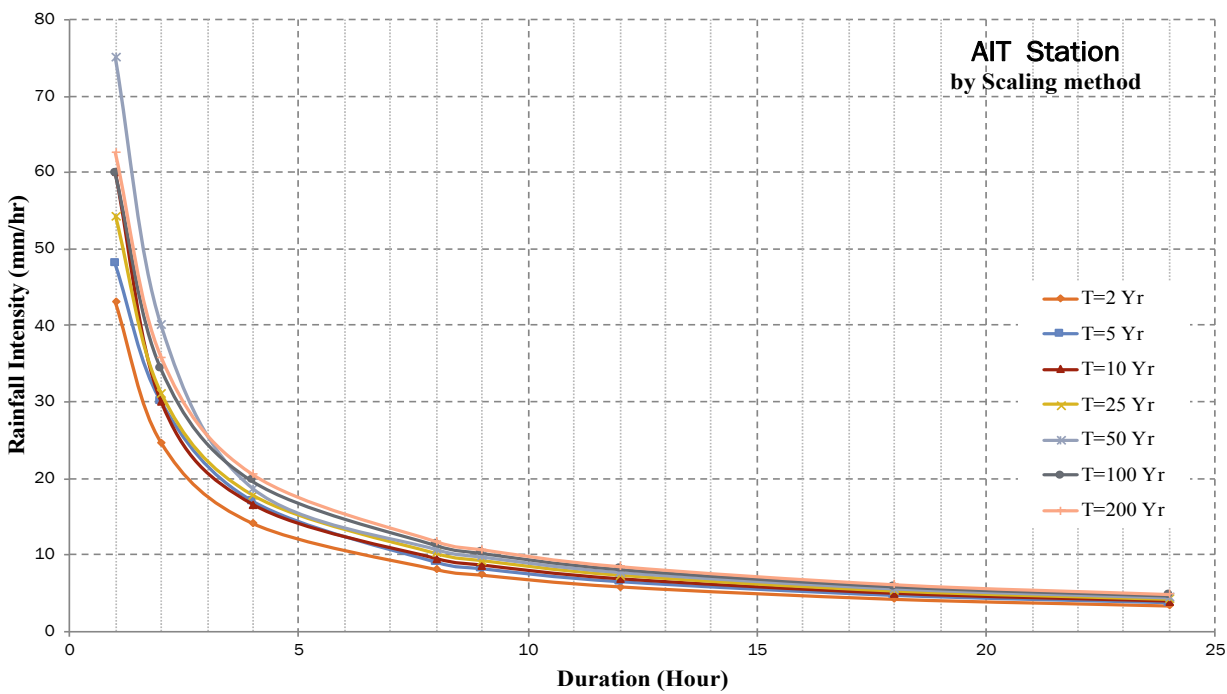

Fig. 19 IDF curves at AIT Station for various return period. 
Kimijima Equation:

$$
i_{d}=\frac{a}{d^{e}+b}
$$

Where $\mathrm{i}$ is the rainfall intensity $(\mathrm{mm} / \mathrm{hr}) ; \mathrm{d}$ is the duration (minutes); $\mathrm{a}, \mathrm{b}$ and $\mathrm{e}$ are the constant parameters related to the metrological conditions.

Frequency analysis techniques are used to develop the relationship between the rainfall intensity, storm duration, and return periods from rainfall data. Analysis of distribution for rainfall frequency is based on the Pearson Type III distribution, which is commonly used in Vietnam for this kind of analysis. The Pearson Type III distribution is written as Eq. (8):

$$
f(x)=\frac{1}{|x| \Gamma(\lambda)}\left[\frac{x-x_{0}}{\alpha}\right]^{\lambda-1} \exp \left[-\frac{x-x_{0}}{\alpha}\right]
$$

Where $\mathrm{x}_{0}$ is the location parameter, $\alpha$ is the scale parameter, $\lambda$ is the shape parameter. The Pearson Type III probability model is used to calculate the rainfall intensity at different rainfall durations and return periods to form the historical IDF curves for each station.

The Pearson Type III distribution used to calculate the rainfall intensity at different rainfall durations and return periods and the maximum rainfall intensity for consider durations and 2, 5, 10, 50, 100 and 200 years return periods, have been determined. The set of IDF curves can be estimated by Kimijima Equation in comparison with IDF constructed by scaling method.

The parameters of Kimijima equation are determined [6] presented in Table 7.

Table 7 The parameters of Kimijima equations as IDF curves.

\begin{tabular}{cccc}
\hline $\begin{array}{c}\text { Return periods } \\
\mathrm{T} \text { (years) }\end{array}$ & $\mathrm{a}$ & $\mathrm{b}$ & $\mathrm{e}$ \\
\hline 200 & 7084.931 & 28.843 & 0.754 \\
100 & 5506.794 & 22.112 & 0.752 \\
50 & 4553.066 & 18.121 & 0.762 \\
20 & 3934.044 & 15.565 & 0.782 \\
10 & 3410.582 & 13.471 & 0.821 \\
5 & 3111.113 & 11.335 & 0.863 \\
2 & 2349.924 & 9.810 & 0.851 \\
\hline
\end{tabular}

In order to verify the new IDF curves, rainfall intensity calculated by empirical IDF equation is considered as observation rainfall intensity compared to rainfall intensity calculated by the new IDF curves. The result illustrated in Figs. 20-23.

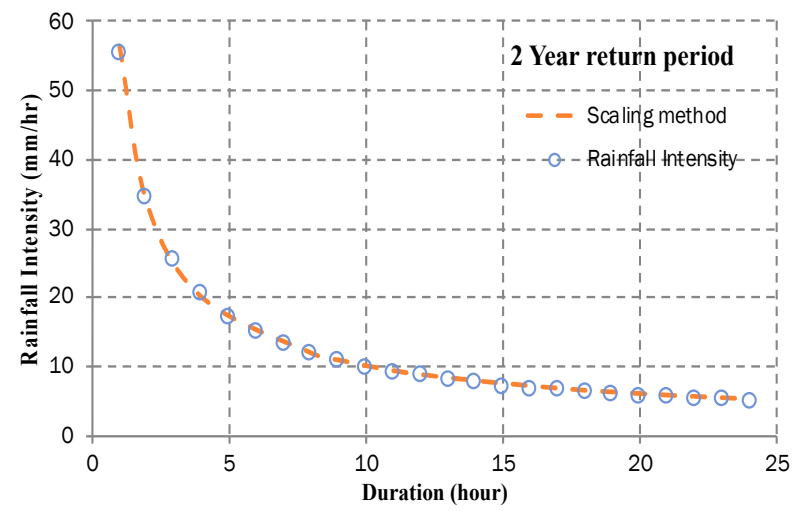

Fig. 20 Scaling method compared to traditional method (2 years return period).

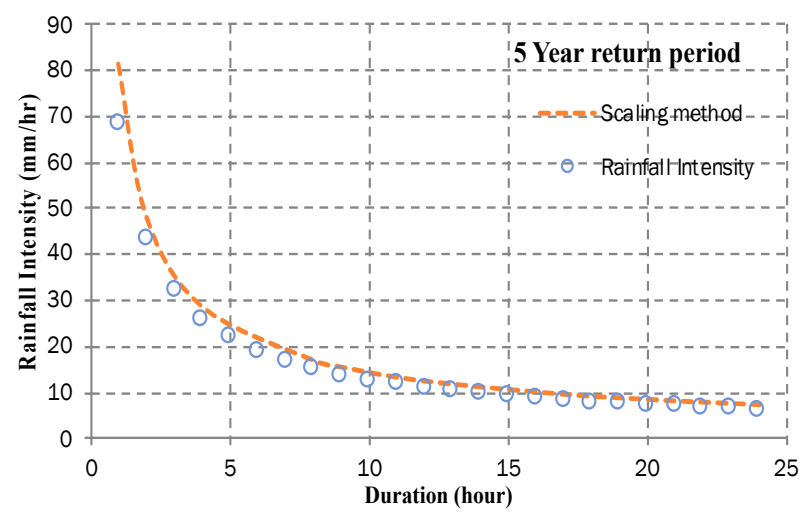

Fig. 21 Scaling method compared to traditional method (5 years return period).

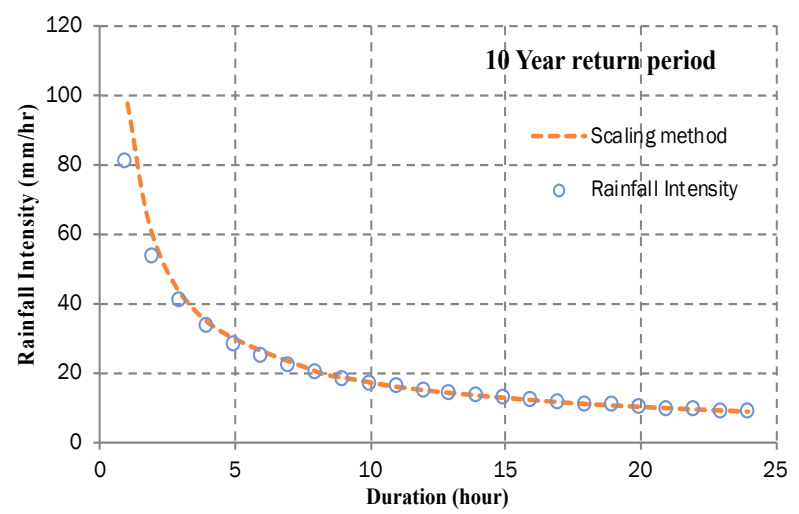

Fig. 22 Scaling method compared to traditional method (10 years return period). 


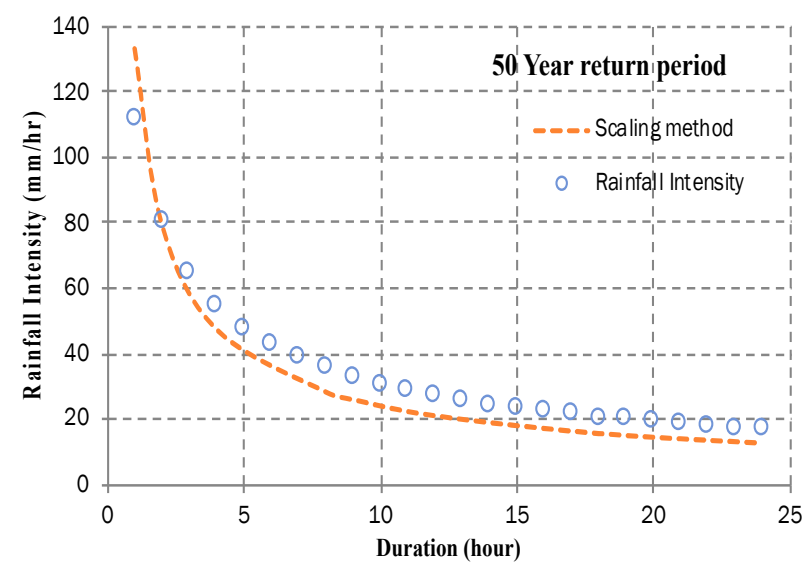

Fig. 23 Scaling method compared to traditional method (50 years return period).

\section{Rainfall Design}

Design storms act as inputs to urban drainage design hydrological models. There exist a variety of ways to define design storms. Some of them are based on a depth of precipitation at a point, on specification of time distribution of rainfall, or on isohyetal maps indicating regional spatial distribution of precipitation. Hyetographs can be constructed from local historical patterns of precipitation, or via synthetic methods able to capture rainfall features of a particular locality. An excellent background on this topic is given by Chow, V. T., et al. [10].

There are several design storm developed in various locations in the world to represent rainfall pattern. The design storm derived based on different assumptions therefore their shapes are different. Generally pattern of design storm can be considered in three parts.

The first part is the rising intensity started from beginning of storm to the peak. This part can be considered as:

One straight line such as Triangular Hyetograph Method;

Two straight lines such as Desbordes Storm Pattern;

Curve such as Chicago Hyetograph Method (Chicago Method).

The second part is the peaks which can be consider as:
One peak such as Triangular Hyetograph Method and Chicago Method;

Continuous peaks such as Sifalda Storm Pattern and Alternative Block Method.

The last part is decay intensity started from the peak to the end of storm. This part can be considered the same as the first part.

Statistical analysis of recorded rainfall data at Lang Station showed that the probability of occurrence of the annual maximum of subset of duration $(0.5,1,3,6$ and 12 hours precipitation) in the same event is about $75 \%$ and the probability of occurrence of annual maximum of the remaining subset $(24,48,72,96$ and 120 precipitation) in the same event is about $70 \%$. This suggests that the existence of a sort of meteorological split of critical events for short and long durations.

Analysis of rainfall data at Lang Station shows that most extreme values of rainfall including hourly, daily occurrence in the storm with duration not less than 6 hours. Therefore, this study applied Chicago Hyetograph with considered storms has up to 6 hour duration and alternating block hyetograph method with rainfall of long low intensity (storm duration up to 24 hours and 48 hours).

Two other design hyetograph are considered: alternating block synthetic storm with the advancement peak coefficient $r$ equal to $0.5,24$ hours duration and one modified alternating block storm with the mean advancement coefficient $r$ equal to $0.153,48$ hours duration.

\subsection{Rainfall Design Developed based on Scaling IDF} Curves

\subsubsection{Chicago Hyetograph Method}

Chicago design storm developed from the relationship of intensity, duration and return period. The computed Chicago design storm for 6, 12, 24 hours duration are show in Figs. 24-26.

The Peak intensity of this design storm shows in Table 8 . It can be seem that peak intensity increase 
with return period but not change when storm duration increase.

\subsection{Alternating Block Hyetographs}

Alternating block and modified alternating block method had applied with time step of one hour, the two design hyetographs for Lang Station with 2 and 10 years return period derived based on scaling DDF curves at Lang Station were computed, as shown in Figs. 27 and 28.

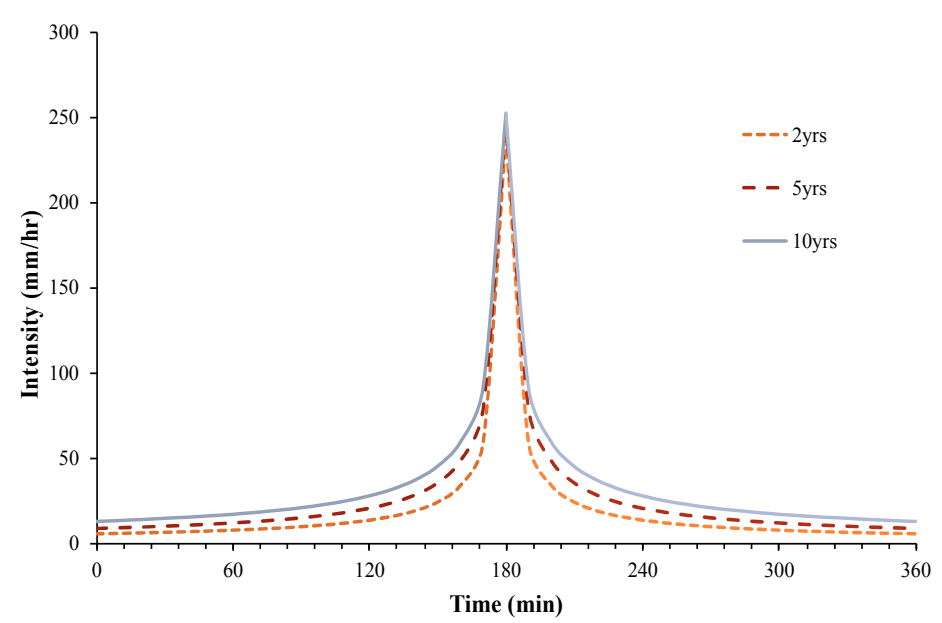

Fig. 24 Chicago design storm hyetographs for Lang Station with 6 hours duration.

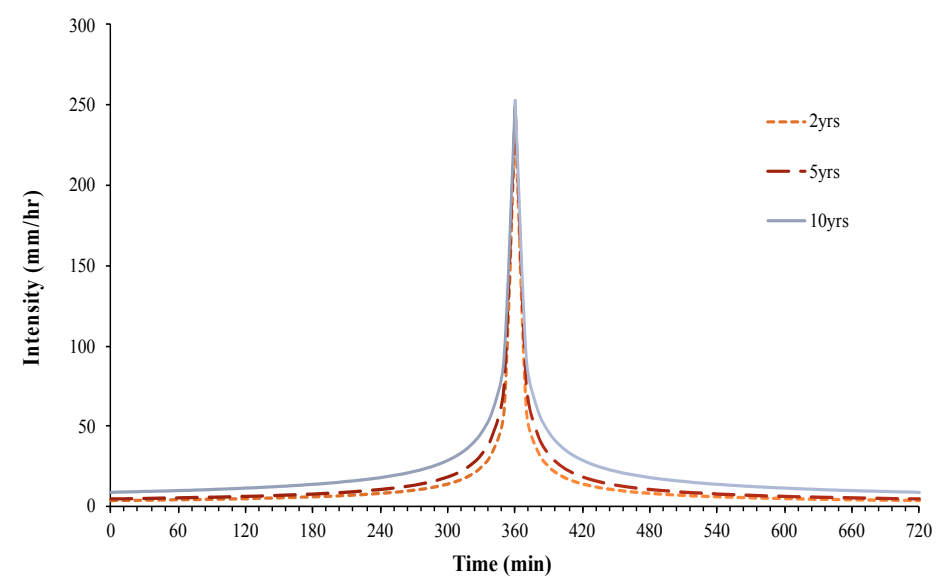

Fig. 25 Chicago design storm hyetographs for Lang Station with 12 hours duration.

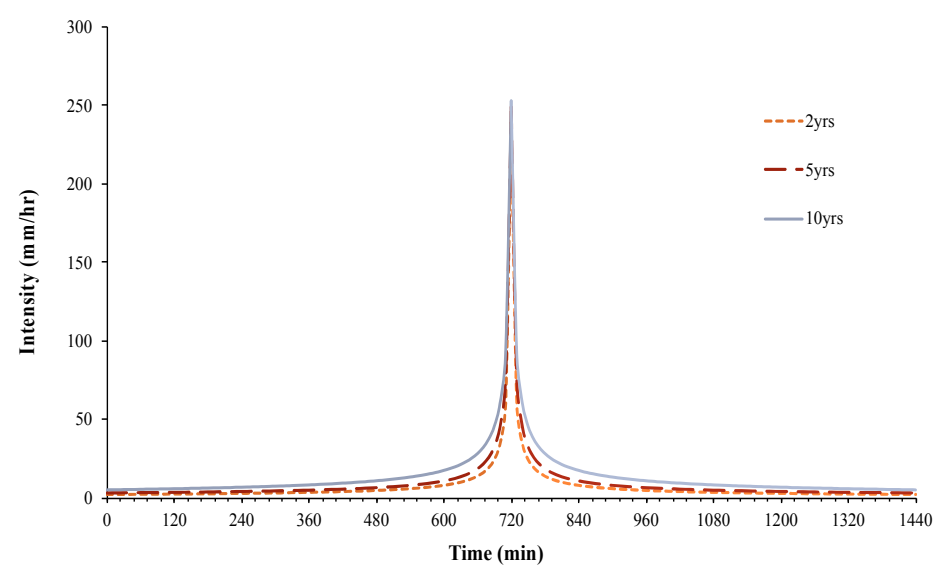

Fig. 26 Chicago design storm hyetographs for Lang Station with 24 hours duration. 
Table 8 Peak intensity from Chigaco design storm based on annual maximum rainfall.

\begin{tabular}{lllll}
\hline Return period (Year) & Peak intensity $(6 \mathrm{hr})$ & Raifall depth $(6 \mathrm{hr})$ & Peak intensity $(12 \mathrm{hr})$ & Raifall depth $(12 \mathrm{hr})$ \\
\hline 2 & 239.44 & 103.74 & 239.44 & 153.96 \\
5 & 248.69 & 135.40 & 248.69 & 189.28 \\
10 & 253.18 & 159.68 & 253.18 & 277.27 \\
\hline
\end{tabular}

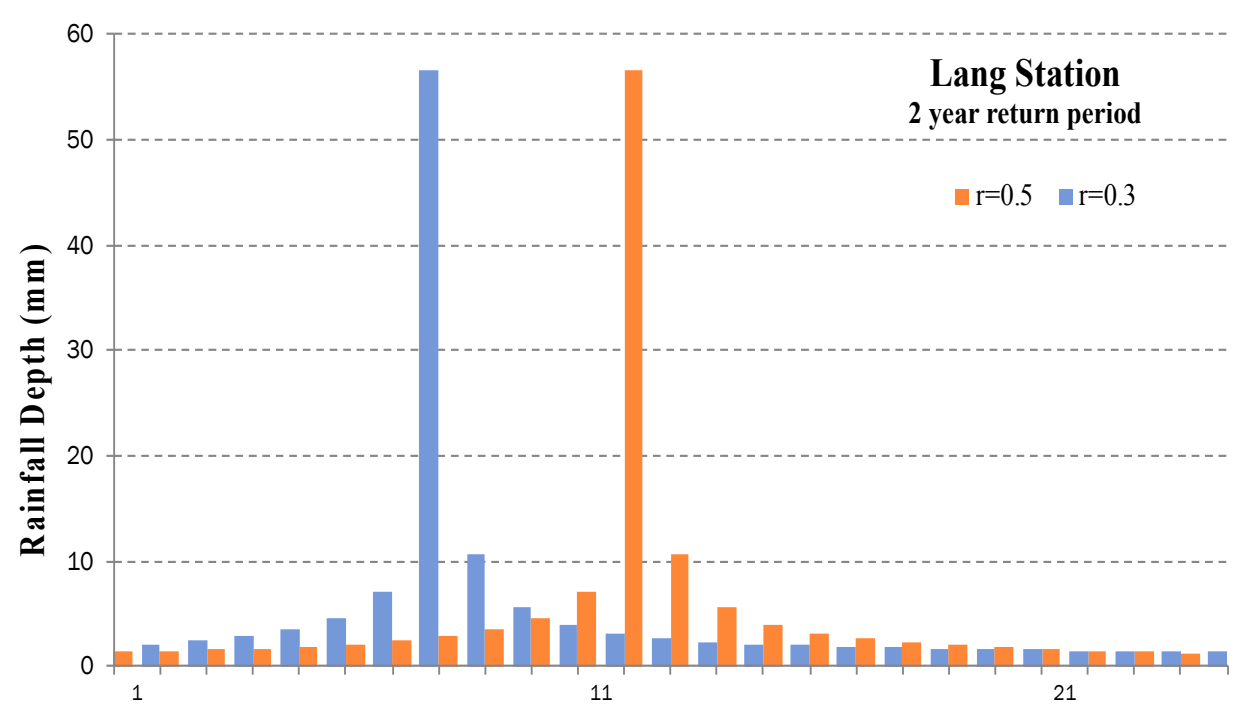

Rainfall Duration (hour)

Fig. 27 24-hour design 2-years return hyetographs for Lang Station.

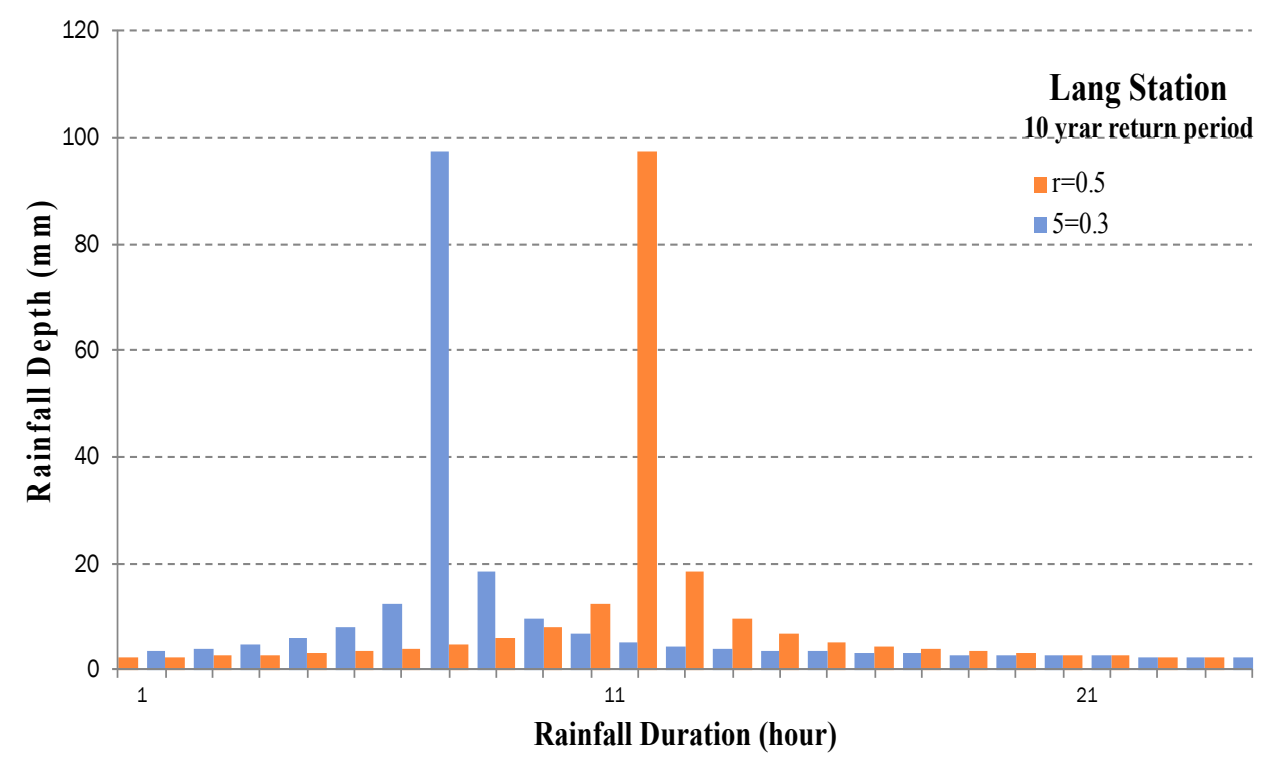

Fig. 28 24-hour design 10-years return hyetographs for Lang Station.

\section{Conclusion and Recommendation}

\subsection{Rainfall Characteristics}

The analysis of 1,508 storms in 1984, 1995, 1996, 2002 and 2008 showed that most of rainfall amount (approximately 70\%) received from rains occurring between 6:0 pm to 6:0 am of the day after that. the daytime usually less rainfall occurrence with only $30 \%$.

The peak rainfall is usually occurred during 0:0 am to $4: 0$ am having approximately $42.98 \%$ of rainfall amount over a day. The peak rainfall likely happen 
earlier in the recent year (36\% rainfall amount over a day occurrence from 6:00 pm to 10:00 pm in 2008).

The analysis also illustrated that approximately $40 \%$ of rainfall events have duration less than 60 minutes. In contrast, only approximately $9 \%$ of rainfall events have duration more than 6 hours but total rainfall depths of these events is approximately.

\subsection{Intensity Duration Frequency Curves}

The simple analytical formulation for rainfall IDF relationship has generalized IDF formulas from daily rainfall based on scaling properties of rainfall time series.

The IDF curves for short duration (sub-daily data) were derived from daily data. The simple scaling property verified by local data, the IDF relationship are deduced from daily rainfall which show good result as compared to IDF curves obtained from short-duration rainfall data.

The IDF curves for Monson climate areas in Vietnam has conducted and applied to Chicago hyetograph and Alternating Block methods.

The scaling properties of rainfall time series also shown good result when applied to conduct to the formulation and construction of IDF curves using data series recorded from AIT meteorological station. The comparison between IDF curves obtained by traditional method [16] show good result with rainfall duration from 60 minutes, with rainfall duration less than 60 minutes, scaling method provided rather high values.

\section{References}

[1] Sherman, C. W. 1931. "Frequency and Intensity of Excessive Rainfalls at Boston, Massachusetts." Transactions ACSE 95: 951-960.

[2] Bernard, M. M. 1932. "Formulas for Rainfall Intensities of Long Durations." Transactions ASCE 96: 592-624.

[3] Watt, W. E., Chow, K. C. A., Hogg, W. D., and Lathem,
K. W. 1986. "A 1-hour Urban Design Storm for Canada." Canadian Journal of Civil Engineering 13 (3): 293-300.

[4] Burlando, P., and Rosso, R. 1996. "Scaling and Multiscaling Models of Depth-urationfrequency Curves for Storm Precipitation." Journal of Hydrology 187: 45-64.

[5] Menabde, M., Seed, A., and Pegram, G. 1999. "A Simple Scaling Model for Extreme Rainfall." Water Resources Research 35: 335-339.

[6] Nhat, L. M., Tachikawa, Y. and Takara, K. 2006. "Establishment of Intensity-Duration-Frequency Curves for Precipitaion in the Monsoon Area of Vietnam." Annuals of Disas. Prve. Rec. Inst., Kyoto Univ., No. 49B, 93-102.

[7] Rodriguez-Iturbe, I., Gupta, V. K., and Waymire, E. 1984. "Scale Considerations in the Modeling of Temporal Rainfall." Water Resources Research 11 (20): 1611-1619.

[8] Koutsoyiannis, D., Kozonis, D., and Manetas, A. 1998. "A Mathematical Framework for Studying Intensity-duration-frequency Relationships." Journal of Hydrology 206: 118-135.

[9] Gupta, V. K., and Waymire, E. 1990. "Multiscaling Properties of Spatial Rainfall and River Flow Distributions." Journal of Geophysical Research 95 (D3): 1999-2009.

[10] Chow, V. T., David, R. M, and Larry, W. M. Eds. 1988. "Applied Hydrology." Water Resources and Environmental Engineering. Singapore. Mc Graw Hill.

[11] Keifer, C. J., and Chu, H. H. 1957. "Synthetic Storm Pattern for Drainage Design." Journal of the Hydraulic Division. ASCE 83 (HY4): 1332/1-1332/24.

[12] Sifalda, V. 1973. "Entwicklung eines Berechnungsregens fur die Bemessung von Kanalnetzen." Gwf-wasser/abwasser 144 (H9): 435-440. (In Germany Languages)

[13] Yen, B. C., and Chow, V. T. 1980. "Design Hyetographs for Small Drainage Structures." Journal of the Hydraulics Division ASCE 106 (HY6): 1055-1076.

[14] Huff, F. A. 1967. "Time Distribution of Rainfall in Heavy Storms." Water Resources Research 3 (4): 1007-1019.

[15] Nguyen, V. T. V. and Pandey G. R. 1994. "Estimation of Short-duration Rainfall Distribution using Data Measured at Longer Time Scales." Water Science and Technology 29 (1- 2): 39-45.

[16] Wiwat, C. 2006. Analysis of Rainfall Pattern for Urban Drainage Design. (Master thesis No. WM-05-1, Asian Institute of Technology, 2006). Bangkok: Asian Institute of Technology. 